IMPACT OF AN EDUCATIONAL INTERVENTION ON FEMALE ATHLETE TRIAD KNOWLEDGE IN FEMALE COLLEGIATE ATHLETES

\author{
A thesis submitted to the \\ Kent State University College \\ of Education, Health, and Human Services \\ in partial fulfillment of the requirements \\ for the degree of Master of Science
}

By

Jessica L. Rennolds

August 2014 
(C) Copyright, 2014 by Jessica L. Rennolds All Rights Reserved 


\author{
A thesis written by \\ Jessica L. Rennolds \\ B.S., Bowling Green State University, 1999 \\ M.S., Kent State University, 2014
}

\begin{abstract}
Approved by
, Director, Master's Thesis Committee

Amy Miracle

, Member, Master's Thesis Committee

Karen Gordon

, Member, Master's Thesis Committee

Tanya Falcone

Accepted by

, Director, School of Health Science

Lynne Rowan

, Dean, College of Education, Health and Human Services

Daniel F. Mahony
\end{abstract}


RENNOLDS, JESSICA L., M.S., August 2014

Nutrition

\section{IMPACT OF AN EDUCATIONAL INTERVENTION ON FEMALE ATHLETE TRIAD KNOWLEDGE IN FEMALE COLLEGIATE ATHLETES ( 87 pp.)}

Director of Thesis: Amy Miracle, Ph.D., R.D., C.S.S.D.

The purpose of this study was to determine if an educational intervention for female collegiate athletes can improve knowledge of the female athlete triad. The participants of the study were 49 female collegiate athletes from Kent State University, an NCAA affiliated university. A Triad Knowledge Questionnaire (TKQ) was distributed to four teams during the first week of this study and again during the following week. After the first administration of the TKQ, one team received an educational presentation, one team an educational handout, one team received both the presentation and handout, and the final team served as the control with no educational intervention given. The TKQ was administered again the following week to determine if there was a difference in female athlete triad knowledge among the different intervention groups.

The results of the study indicated there was a significant difference $(p<.001)$ between groups on TKQ posttest performance. Furthermore, a repeated measures ANOVA indicated a significant improvement $(p<.001)$ between pretest and posttest scores for the intervention groups. Overall, the findings of this study revealed that an educational intervention for female collegiate athletes improved knowledge of the female athlete triad. 


\section{ACKNOWLEDGMENTS}

First, I would like to thank Dr. Amy Miracle, my thesis advisor, for her unwavering support and patience throughout this process. Words cannot express how grateful I am for all her inspiration, guidance, and assistance. Without her, this would not have been possible.

I would like to further thank my committee members, Dr. Karen Gordon and Ms. Tanya Falcone, for their critique, expertise, and encouragement which have been invaluable.

To the athletic department, specifically the coaches of the soccer, softball, basketball, and track and field teams, thank you for giving me the opportunity to meet with your student athletes. I want to thank the athletes from these teams for taking the time to participate in my study.

To my family, your belief in my abilities, endless encouragement, and constant support allowed me to complete this endeavor. I am forever indebted to my sisters, Justine Pickett and Jennifer Simon, for helping me with editing and formatting. I owe my deepest gratitude to my niece, Rebecca Simon, who unknowingly led me down this path. 


\section{TABLE OF CONTENTS}

ACKNOWLEDGMENTS

LIST OF TABLES

vii

LIST OF FIGURES viii

\section{CHAPTER}

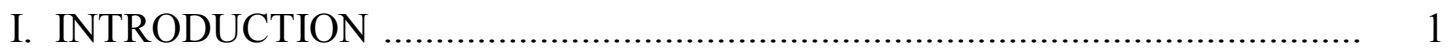

Statement of the Problem ................................................................................ 3

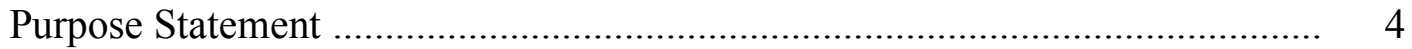

Research Hypothesis ................................................................................ 4

Operational Definitions ............................................................................... 5

II. REVIEW OF LITERATURE …………………...................................... 6

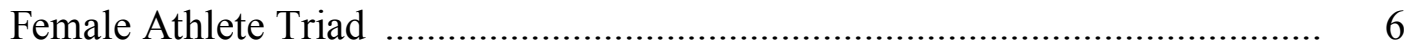

Energy Availability .................................................................................... 7

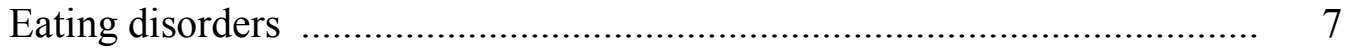

Inadvertent low energy availability ........................................................ 10

Menstrual Function .......................................................................... 11

Bone Mineral Density .................................................................................. 12

Prevalence of the Female Athlete Triad ......................................................... 13

Risk for the Female Athlete Triad ………………………………………... 16

Prevention of the Female Athlete Triad ........................................................ 19

Treatment of the Female Athlete Triad ........................................................ 20

Dietary Intake ........................................................................................ 21

Recommendations for Athletic Performance …………................................ 21

Dietary Intake of Adolescent Athletes ........................................................... 22

Dietary Intake of Female Collegiate Athletes ................................................... 23

Nutrition Knowledge .................................................................................... 24

General Nutrition Knowledge ................................................................. 24

Nutrition Knowledge of all Athletes .............................................................. 24

Nutrition Knowledge of Female Collegiate Athletes ...................................... 26

Female Athlete Triad Knowledge ……………………….............................. 27

Educational Interventions ....................................................................... 28

Intervention with College Women .......................................................... 28

Interventions with Collegiate Athletes ........................................................... 29

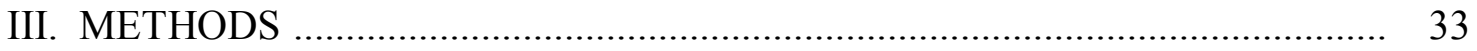

Research Design ..................................................................................... 33

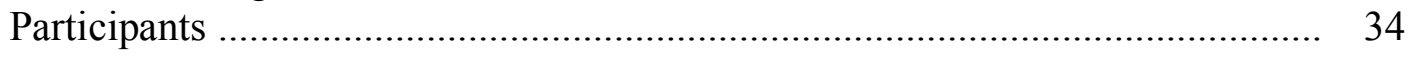




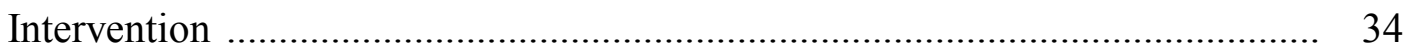

Measurement Instrument ...................................................................... 35

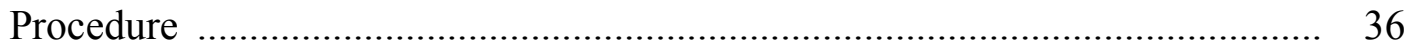

Data Analysis ....................................................................................... 37

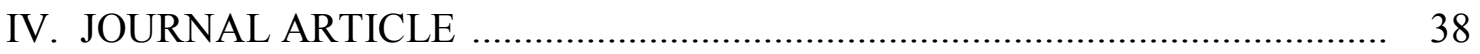

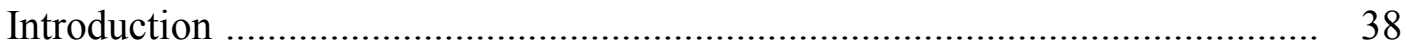

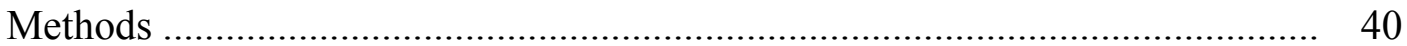

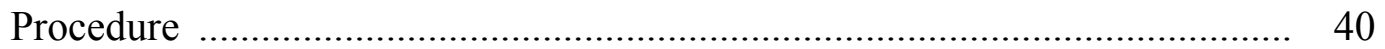

Measurement Instrument ......................................................................... 41

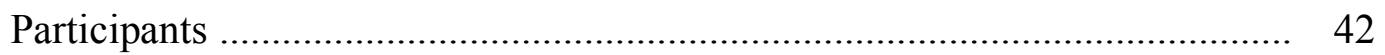

Statistical Analysis ............................................................................ 42

Results ........................................................................................ 43

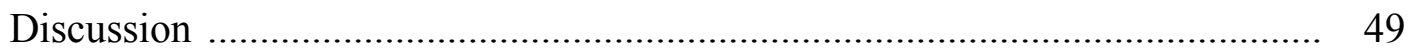

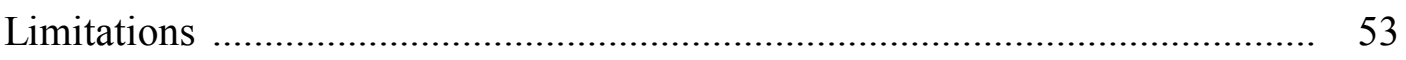

Applications ......................................................................................... 54

Recommendations for Future Research ………………................................ 55

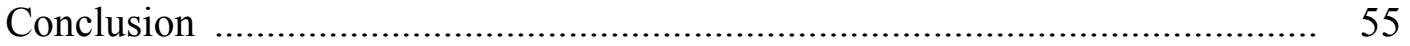

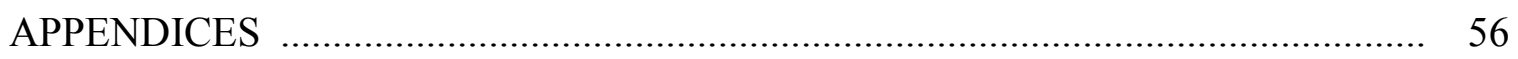

APPENDIX A. EDUCATIONAL PRESENTATION ………………………....... 57

APPENDIX B. EDUCATIONAL HANDOUT ………………………………..... 64

APPENDIX C. TRIAD KNOWLEDGE QUESTIONNAIRE ............................... 67

APPENDIX D. RECRUITMENT EMAIL …………...................................... 72

APPENDIX E. CONSENT FORM …………………......................................... 74

APPENDIX F. FREQUENCY DISTRIBUTIONS TABLE _................................... 77

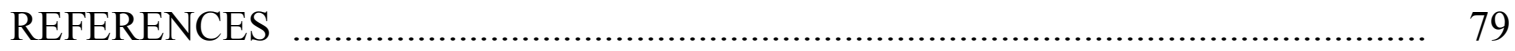




\section{LIST OF TABLES}

Table

Page

1. Demographic Characteristics of Division I Female Collegiate Athletes $(N=49)$.. 44

2. Means and Standard Deviations of Triad Knowledge Questionnaire Scores in Division I Female Collegiate Athletes $(N=49)$

3. Frequency Distribution of Division I Female Collegiate Athletes' Responses to when Female Athlete Triad Screening Occurs at their University 48

4. Means and Standard Deviations of Division I Female Collegiate Athletes' Rank of Available Resources for Female Athlete Triad Information and Support $(N=44)$ 


\section{LIST OF FIGURES}

Figure $\quad$ Page

1. Mean Triad Knowledge Questionnaire scores from pretest to posttest by group

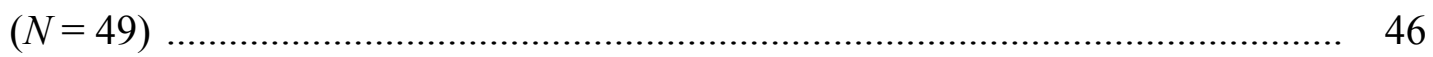

2. Triad Knowledge Questionnaire performance at posttest ................................. 47 


\section{CHAPTER I}

\section{INTRODUCTION}

Over the past three decades the number of women participating in The National Collegiate Athletic Association (NCAA) has increased from approximately 74,239 to 198,103, a 267\% increase (National Collegiate Athletic Association, 2012). Optimal nutrition intake is needed to fuel this physical activity and to maximize performance and recovery (American College of Sports Medicine, American Dietetic Association, \& Dietitians of Canada, 2009). However, female athletes may intentionally or unintentionally restrict their caloric intake or over train in an effort to excel at their sport or to achieve a lean physique (Pantano, 2006). This may result in an energy deficit which puts these female athletes at risk of the female athlete triad, also referred to as the triad.

The female athlete triad is a syndrome that consists of three interconnected components: energy availability, menstrual function, and bone mineral density, which encompasses a range from optimal health to disease (Nattiv et al., 2007). At the severest end of the spectrum, clinical conditions including eating disorders, functional hypothalamic amenorrhea (absence of menses), and osteoporosis (low bone density) may be present (Nattiv et al., 2007). Low energy availability leads to amenorrhea, which in turn negatively affects bone health (Nattiv et al., 2007).

Although all active girls and women are at risk of developing the female athlete triad, female collegiate athletes are a population of particular concern because studies have shown a high prevalence of eating disorders, specifically subclinical eating disorders (Carter \& Rudd, 2005; Greenleaf, Petrie, Carter, \& Reel, 2009). Optimal 
nutrition intake is considered essential in the prevention of the female athlete triad (Zawila, Steib, \& Hoogenboom, 2003). However, female athletes may inadvertently not consume enough calories to support their activity due to their schedules, lack of food options, or inadequate nutrition knowledge (Beals \& Meyer, 2007).

Numerous studies have assessed the nutrition knowledge and dietary intake of female collegiate athletes. This research has indicated there is a lack of nutrition knowledge amongst female collegiate athletes across a variety of sports (Hoogenboom, Morris, Morris, \& Schaefer, 2009; Hornstrom, Friesen, Ellery, \& Pike, 2011; Zawila et al., 2003). Furthermore, the dietary intake of female collegiate athletes is neither within the Recommended Dietary Allowances (RDA) nor the sports nutrition guidelines (Hoogenboom et al., 2009; Shriver, Betts, \& Wollenberg, 2013; Valliant, Emplaincourt, Wenzel, \& Garner, 2012). The results of these studies suggest female collegiate athletes may not understand the importance of energy balance or how to properly fuel their bodies. This is cause for concern since it can lead to low energy availability, the key component of the female athlete triad.

Education is essential to the prevention of the female athlete triad (Miller, Kukuljan, Turner, van der Plight, \& Ducher, 2012; Nattiv et al., 2007; Staurowsky et al., 2009). Female athletes who do not understand the connection between the components of the triad may not realize they have the syndrome until they have a stress fracture, a common first symptom (Sundgot-Borgen \& Torstveit, 2003). A lack of outward signs could indicate that female athletes may disregard the severity of low energy availability 
and amenorrhea. This supports the importance of educating female athletes about the triad in order to prevent its occurrence.

A recent study by Miller et al. (2012) indicated that female exercisers lack knowledge about the three components of the female athlete triad and how they are interconnected. The female exercisers in this study did not understand the negative impact menstrual disturbances have on bone health and even thought irregular periods were a normal part of being active. Some female athletes do not find amenorrhea worrisome and even consider it convenient (Beals \& Meyer, 2007; Sundgot-Borgen \& Torstveit, 2003). In addition to athletes, collegiate coaches have inadequate knowledge about the components of the triad and also consider menstrual dysfunction normal for physically active females (Pantano, 2006). This is of concern since athletes have identified coaches as a source of nutrition information (Hoogenboom et al., 2009; Zawila et al., 2003), but coaches have inadequate sport nutrition knowledge (Torres-McGehee et al., 2012). This may result in misinformation passed on to female collegiate athletes who may already be unaware of the consequence of inadequate energy intake.

\section{Statement of the Problem}

The female athlete triad is of concern because the components, occurring in combination or separately, not only affects physical performance but can lead to morbidity and mortality (Otis, Drinkwater, Johnson, Loucks, \& Wilmore, 1997). Increasing knowledge of the female athlete triad through education is considered essential to its prevention (Sanborn, Horea, Siemers, \& Dieringer, 2000; Staurowsky et al., 2009). However, a problem among some NCAA Division I schools is that female 
athlete triad education is not a requirement, although educational programs are available at some of these institutions (Beals, 2003). Furthermore, not all NCAA schools have a registered dietitian on staff (Karpinski, 2012) who can educate athletes about the importance of fueling their bodies in order to maintain energy balance.

Only two studies have addressed knowledge of the female athlete triad among female exercisers and athletes (Miller et al., 2012; Simpson et al., 1998). In addition to knowledge, surveys used in these studies focused on attitudes and behaviors about the female athlete triad and its components. However, neither of these studies used a questionnaire to specifically measure knowledge of the female athlete triad.

Furthermore, to date, no one has examined if an educational intervention can improve knowledge of the female athlete triad. Therefore, it is imperative to determine the impact of education on female collegiate athletes and their knowledge of the female athlete triad.

\section{Purpose Statement}

The purpose of this study was to assess if an educational intervention would improve knowledge of the female athlete triad among female collegiate athletes at a Midwestern NCAA affiliated university.

\section{Research Hypothesis}

Female athlete triad knowledge will differ among female collegiate athletes based on the intervention strategy. 


\section{Operational Definitions}

Disordered Eating: abnormal eating patterns that do not meet the diagnostic criteria of an eating disorder

Educational Intervention: some form of educational teaching that addresses a specific issue or topic to increase knowledge or understanding about said issue or topic Energy availability: amount of energy available to support bodily functions after subtracting energy expended during exercise from dietary energy intake (American College of Sports Medicine, American Dietetic Association, \& Dietitians of Canada, 2009)

Female athlete triad (Triad): a syndrome that consists of three interconnected components: energy availability, menstrual function, and bone mineral density, encompassing a range of optimal health to disease (Nattiv et al., 2007) Female collegiate athletes: females participating in a sanctioned NCAA sport at a university or college Knowledge: information a person knows about a particular topic Subclinical eating disorders: eating disorders that do meet diagnosable criteria but have some symptoms of clinical eating disorders such as anorexia nervosa and bulimia nervosa (Sanford-Martens et al., 2005) 


\section{CHAPTER II}

\section{REVIEW OF LITERATURE}

\section{Female Athlete Triad}

The female athlete triad, defined in 1992 as a syndrome of three disorders: disordered eating, amenorrhea, and osteoporosis was the focus of a consensus conference held by the American College of Sports Medicine (ACSM) where attendees strategized on how to approach this emerging syndrome (Yeager, Agostini, Nattiv, \& Drinkwater, 1993). At the conference it was determined that educational materials and guidelines should be created along with a position paper by the ACSM (Yeager et al., 1993). The ACSM published a position stand on the female athlete triad in 1997 which used the original definition of disordered eating, amenorrhea, and osteoporosis (Otis, Drinkwater, Johnson, Loucks, \& Wilmore, 1997). However, this definition limited the number of females with the female athlete triad to those who had these specific disorders (TheinNissenbaum, 2013). For example, Burrows, Shepherd, Bird, Macleod, and Ward (2007) found that $22 \%$ of the females in their study were considered at risk for health problems using the original criteria, but an additional 33\% were at risk using broader terms such as menstrual irregularities and osteopenia. As research on the female athlete triad expanded, the ACSM published an updated position stand in 2007 which included a new definition (Beals \& Meyer, 2007). The current definition classifies the female athlete triad as a syndrome with three related components: energy availability, menstrual function, and bone mineral density, which can range from a state of health to disease (Nattiv et al., 2007). 


\section{Energy Availability}

Energy availability is the amount of energy available for the body to function after subtracting energy expended from energy intake (American College of Sports Medicine, American Dietetic Association, \& Dietitians of Canada, 2009). Energy availability ranges from a state of optimal energy availability to low energy availability (Nattiv et al., 2007). Optimal energy availability is achieved when an athlete consumes enough calories to support the amount of energy she is expending (Nattiv et al., 2007). Low energy availability occurs when the amount of energy expended exceeds the amount of dietary energy intake (Manore, Kam, \& Loucks, 2007). A female athlete may have low energy availability for several reasons including: (a) eating disorders or disordered eating, (b) intentional dietary restriction in order to achieve weight loss, or (c) inadvertently failing to increase dietary intake while increasing the amount of energy expended (Loucks, Kiens, \& Wright, 2011). A prolonged state of low energy availability is detrimental to the health of female collegiate athletes specifically because it can lead to amenorrhea (Nattiv et al., 2007). A chronic energy deficiency suppresses reproduction in order to conserve energy for more vital processes like cellular maintenance and circulation (Wade \& Jones, 2004).

Eating disorders. Clinical eating disorders, such as anorexia nervosa and bulimia nervosa, meet specific diagnostic criteria in the Diagnostic and Statistical Manual of Mental Disorders, $5^{\text {th }}$ Edition (DSM-5). This manual, published by the American Psychiatric Association, specifies the clinical criteria required to receive a diagnosis for various mental disorders. The DSM-5 was published in May of 2013, thus, 
most of the literature references the previous manual, the Diagnostic and Statistical Manual of Mental Disorders, Fourth Edition, Text Revision (DSM-IV-TR). This review will use definitions from the current manual, DSM-5, with an explanation of how it differs from DSM-IV-TR. In addition, prevalence rates referenced will be based on DSM-IV-TR criteria since the majority of the literature uses this manual, but reference will also be made to the few articles that have been published recently using the DSM-5 criteria. Furthermore, diagnostic criteria is the same in both the DSM-IV-TR and DSMIV but the text of the DSM-IV-TR was updated (American Psychiatric Association, 2000). Therefore, in regards to diagnostic criteria these versions can be used interchangeably and cited articles reference the DSM-IV.

Anorexia nervosa can be classified as a restricting type or binge-eating/purging type and involves restricting caloric intake resulting in a low body weight, an intense fear of gaining weight, and a distorted view of body shape and weight (American Psychiatric Association, 2013). In addition to these criteria, the DSM-IV-TR also included amenorrhea as criteria for anorexia nervosa diagnosis (American Psychiatric Association, 2000). An average prevalence rate of anorexia nervosa for young females based on the DSM-IV criteria is $0.3 \%$ (Hoek, 2006; Hoek \& van Hoeken, 2003). In a study of 425 female collegiate athletes, $3.3 \%$ reported a clinical diagnosis of anorexia nervosa (Beals \& Manore, 2002). Additionally, in a study involving female high school and university students, 18 met the criteria for anorexia nervosa based on the DSM-IV criteria but that number increased to 21 when the proposed DSM-5 criteria was used (Machado, Gonçalves, \& Hoek, 2013). 
Diagnostic criteria for bulimia nervosa include: (a) binge eating; (b) compensating for binging by purging, fasting, or excessively exercising; (c) practicing these behaviors once a week for three months; and (d) basing their self-esteem on weight and body shape (American Psychiatric Association, 2013). DSM-IV-TR criteria differs from this in that the requirement for compensatory behavior was twice a week (American Psychiatric Association, 2000). An average prevalence rate of bulimia nervosa for young females is 1\% (Hoek, 2006; Hoek \& van Hoeken, 2003). An NCAA study found that $1.1 \%$ of 562 Division I female collegiate athletes experienced bulimia nervosa based on the DSM-IV criteria (Johnson, Powers, \& Dick, 1999). The study by Machado et al. (2013) found 14 cases of bulimia nervosa using the DSM-IV criteria, but when the proposed DSM-5 criteria were used, there were 18 females diagnosed with bulimia nervosa.

Eating disorders that do not meet the diagnostic criteria to be classified as anorexia or bulimia are categorized as other specified feeding or eating disorder (reasons for not meeting criteria identified) and unspecified feeding or eating disorder (reasons not identified) (American Psychiatric Association, 2013). In the DSM-IV-TR, eating disorders that did not meet the specific criteria were classified as an eating disorder not otherwise specified (EDNOS) (American Psychiatric Association, 2000). The prevalence of EDNOS based on the DSM-IV criteria was $2.79 \%$ among females in high school and college, but decreased to $1.8 \%$ when the proposed DSM-5 criteria were applied (Machado et al., 2013).

Subclinical eating disorders do not meet diagnostic criteria but include some of the symptoms of anorexia and bulimia (Sanford-Martens et al., 2005). Studies have 
shown the prevalence of subclinical eating disorders among female collegiate athletes to be approximately 14\% to 25\% (Carter \& Rudd, 2005; Greenleaf et al., 2009; SanfordMartens et al., 2005). This high prevalence is of particular concern since the subclinical nature of the symptoms may not be as easily identified, and thus treated, as a clinical eating disorder (Greenleaf et al., 2009). Furthermore, subclinical eating disorders are believed to initiate clinical eating disorders (Beals, 2000).

Inadvertent low energy availability. Low energy availability may also occur if an athlete inadvertently does not consume enough calories to support the amount of energy expended (Loucks et al., 2011). Experiments have shown that an energy deficit caused by exercise expenditure does not increase hunger like an energy deficit due to caloric restriction (Hubert, King, \& Blundell, 1998). In this study examining the effects of an energy deficit caused by caloric restriction or exercise energy expenditure within participants, the energy deficit by caloric restriction caused an increase in hunger whereas the energy deficit by energy expenditure had no significant effect on hunger. Furthermore, the results of the study also indicated that an energy deficit due to a low caloric breakfast led to an increased energy consumption at lunch (Hubert et al., 1998). Another study found that physical activity did not induce an increase in energy intake and even decreased hunger (Bergouignan et al., 2010). In this study, 16 women were subjected to 60 days of bed rest, eight of the women exercised in a supine position while the other eight did not exercise at all. Results of the study reveal that the exercise group had a negative energy balance. Although a small negative energy balance also existed in the controls, it was attributed to the loss of fat-free mass (Bergouignan et al., 2010). 
Therefore, according to Loucks et al. (2011) “endurance athletes should not wait until they are hungry to eat but eat by discipline since appetite is not a reliable indicator of energy requirements" (p. S13).

\section{Menstrual Function}

Menstrual function can range from eumenorrhea (normal menses) to amenorrhea (absence of menses) (Nattiv et al., 2007). Amenorrhea can further be classified as primary amenorrhea (delayed menarche) or secondary amenorrhea (absence of menses after menarche) (Nattiv et al., 2007). In addition, functional hypothalamic amenorrhea refers to absence of the menses as a result of low energy availability (Loucks, Verdun, \& Heath, 1998). Menstrual function also includes menstrual irregularities such as oligomenorrhea (cycles lasting more than 35 days), luteal deficiency (low progesterone in luteal phase), and anovulation (menstrual cycle with no ovulation) (Manore et al., 2007). Amenorrhea and oligomenorrhea are clinical disorders that are easily noticeable by those experiencing them, but subclinical menstrual disorders like luteal deficiency and anovulation are asymptomatic (Manore et al., 2007). These menstrual disturbances can be determined by measuring hormone levels throughout the entire menstrual cycle (De Souza et al., 2010). Measurement of daily hormone concentrations among sedentary and exercising women found a $4.2 \%$ and $50 \%$ prevalence rate of subclinical menstrual disorders, respectively (De Souza et al., 2010).

Eumenorrhea occurs due to regulation of the pituitary secretion of follicle stimulating and luteinizing hormones by the hypothalamic gonadotropin-releasing hormone, which allows an appropriate amount of estrogen to be released from the ovary 
(Javed, Tebben, Fischer, \& Lteif, 2013). Functional hypothalamic amenorrhea occurs as a result of disturbances in the release of gonadotropin-releasing hormone and luteinizing hormone from the hypothalamus and pituitary, respectively (Loucks, Mortola, Girton, \& Yen, 1989). Disruption of the luteinizing hormone has been shown to occur when energy availability falls below $30 \mathrm{kcal} / \mathrm{kg}$ lean body mass per day (Loucks \& Thuma, 2003). Energy deficiency in combination with hypoestrogenism in an amenorrheic athlete results in bone loss by suppressing bone formation and increasing bone resorption (De Souza et al., 2008).

\section{Bone Mineral Density}

Bone mineral density (BMD) ranges from optimal bone density to osteoporosis (Nattiv et al., 2007). Bone mineral density, measured by dual energy x-ray absorptiometry (DXA), is grams of bone mineral content per area (Nichols, Sanborn, \& Essery, 2007). The International Society for Clinical Densitometry (ISCD) classifies low bone mineral density as a $\mathrm{Z}$-score $\leq-2.0$ in premenopausal women but a diagnosis of osteoporosis requires secondary risk factors such as hypogonadism, glucocorticoid use, or hyperparathyroidism (The Writing Group for the ISCD Position Development Conference, 2004). The ACSM uses a similar definition of osteoporosis but the definition of low bone mineral density is "a history of nutritional deficiencies, hypoestrogenism, stress fractures, and/or other secondary clinical risk factors for fracture together with a BMD Z-score between -1.0 and -2.0” (Nattiv et al., 2007, p. 1870).

BMD along with bone quality determines bone strength (National Institutes of Health Consensus Development Panel, 2001). Bone quality is described as "a composite 
of properties that make bone resist fracture, such as its microarchitecture, accumulated microscopic damage, the quality of collagen, mineral crystal size, and bone turnover" (Licata, 2009, p. 331). The skeletal disorder osteoporosis is associated with a decrease in bone strength which increases the risk of stress fractures (National Institutes of Health Consensus Development Panel, 2001).

Bone remodeling, the process of bone resorption and formation, occurs continuously throughout life (Nichols et al., 2007). According to Nichols et al. (2007) bone remodeling is affected by three factors: “(a) hormonal status, (b) weight-bearing physical activity, and (c) dietary intake (particularly calcium)" (p. 1003). A change in the rate of bone remodeling occurs within five days of restricting energy availability below $30 \mathrm{kcal} / \mathrm{kg}$ lean body mass per day resulting in an increase in bone resorption and a decrease in bone formation (Ihle \& Loucks, 2004). Another study on bone turnover found an energy and estrogen deficiency led to the suppression of osteoblast function and an increase in osteoclast function which was determined by measurement of bone formation and resorption markers (De Souza et al., 2008).

A study by Mudd, Fornetti, and Pivarnik (2007) measured the bone mineral density of NCAA Division I female collegiate athletes across a variety of sports. Results indicated that runners had the lowest total body bone mineral density followed by swimmers and divers (Mudd et al., 2007).

\section{Prevalence of the Female Athlete Triad}

The prevalence of the Triad is estimated to range from $0 \%$ to $16 \%$ for all three components, $3 \%$ to $27 \%$ for two or more components, and $16 \%$ to $60 \%$ for one of the 
components (Gibbs, Williams, \& De Souza, 2013). Variation in the prevalence estimates are a result of different definitions of the components of the female athlete triad and differences in methodology of the various research studies (Gibbs et al., 2013). For example, Beals and Hill (2006) defined the third component of the female athlete triad as low bone mineral density which is consistent with the ACSM definition, but in a prevalence study by Reel, SooHoo, and Doetsch (2007), the third component was defined as musculoskeletal injuries. Another limitation to prevalence studies is that most of the studies have investigated the prevalence of disordered eating and clinical eating disorders, but only one examined the prevalence of low energy availability (Gibbs et al., 2013; Hoch et al., 2009).

Hoch et al. (2009) determined the prevalence of the female athlete triad among female high school athletes which included a comparison with a non-athletic control group. Results of the study indicated the majority of the athletes and controls, $78 \%$ and $65 \%$ respectively, met the criteria for one or more of the components of the female athlete triad. Only one athlete and one control out of 80 participants for each group had all three components of the triad defined for this study as low energy availability, menstrual dysfunction, and low bone mineral density. For this study a Z-score of -2 and -1 was used to determine low bone mineral density based on the ISCD and ACSM criteria. Hoch et al. noted that since athletes in weight bearing sports have higher bone mineral densities, using a score of -2 to determine low bone mineral density could mean athletes would already have substantial bone loss at a time when bone building is crucial. 
Like the previous study with high school athletes, the prevalence of female collegiate athletes suffering from one or two components of the female athlete triad are higher than those with all three (Beals \& Hill, 2006; Reel et al., 2007). A prevalence study involving 112 female collegiate athletes at a Division II university found one athlete with all three components of the female athlete triad (Beals \& Hill, 2006). Fiftynine athletes had one component of the triad, with 28 meeting criteria for disordered eating, 29 meeting criteria for menstrual dysfunction, and two athletes with low bone mineral density. A total of 10 athletes had two components of the triad, one athlete met the criteria for disordered eating and low bone mineral density and the other nine met criteria for disordered eating and menstrual dysfunction. Interestingly, the athlete with all three components of the triad participated in cross-country, which is considered a risk factor (Otis et al., 1997). A Z score of -2.0 was used as the criteria for low bone mineral density but when a score of -1.0 was applied, the number of athletes with all three components increased to three, all of whom were in lean-build sports. However, Beals and Hill (2006) did not find a difference in prevalence among lean-build versus non-lean build sports except for menstrual dysfunction, which had a higher prevalence among lean-build sports.

A similar study that included 451 Division I female collegiate athletes found five athletes with all three components of the female athlete triad (Reel et al., 2007). However, unlike Beals and Hill (2006), this study did not measure bone mineral density by dual-energy x-ray absorptiometry. Instead, the researchers used the occurrence of 
stress fractures and muscle injuries to determine the third component of the female athlete triad which they defined as musculoskeletal injuries (Reel et al., 2007).

\section{Risk for the Female Athlete Triad}

At the time the female athlete triad was defined, all female adolescent athletes were considered at risk with only some adult female athletes (Yeager et al., 1993). It was acknowledged that nonathletes may experience the disorders of the triad but athletes were considered to be at an increased risk (Yeager et al., 1993). This included athletes in endurance or appearance sports who felt pressured to succeed in their sport and also to maintain a lean physique (Yeager et al., 1993). The 1997 ACSM position stand identifies all physically active females as being at risk of the female athlete triad (Otis et al., 1997). Sports that focus on a lean build, such as gymnastics and distance running, or sports that require revealing clothing, such as swimming and diving, are considered risk factors (Otis et al., 1997). In addition, nonathletes and physically active females who are not participating in sports may also experience the female athlete triad (Otis et al., 1997).

A study by Thompson and Gabriel (2004) indicated that female noncollegiate athletes report eating disorders, menstrual disturbances, and injuries due to exercise. This noncollegiate athletic group consisted of 19 physically active female college students who reported approximately 40 minutes of exercise per day. Thirty-seven female collegiate athletes from cheerleading, track, tennis, volleyball, cross-country, and soccer also participated in the study. Thompson and Gabriel (2004) surveyed both groups regarding risk factors of the female athlete triad. Results of the study indicated that both female collegiate athletes and noncollegiate athletes exhibit behaviors that put them at 
risk of the female athlete triad. Self-report of eating disorders were $8.6 \%$ among female collegiate athletes, but $11.1 \%$ among noncollegiate athletes. Amenorrhea was not reported by any of the noncollegiate athletes, but $2.6 \%$ of collegiate athletes reported experiencing this menstrual disturbance. Moreover, oligomenorrhea was reported by both groups, with collegiate athletes reporting $30.6 \%$ and noncollegiate athletes reporting $16.7 \%$. Stress fractures or other injuries due to exercise or competition were reported by $67.6 \%$ of collegiate athletes and $27.9 \%$ noncollegiate athletes (Thompson \& Gabriel, 2004).

A similar study by Torstveit and Sundgot-Borgen (2005) indicated that the female athlete triad occurs not only in elite athletes but also in nonathletic controls. Results of the study indicated that eight elite athletes experienced all three components of the triad whereas five controls experienced all three. Of the eight elite athletes meeting criteria for all three components of the female athlete triad, six participated in lean build sports. Prevalence of any combination of two components ranged from $5.4 \%$ to $26.9 \%$ for elite athletes and $12.4 \%$ to $15.2 \%$ for nonathletic controls. Although these results are important in that it supports the need to educate all physically active females about the female athlete triad, it is not without controversy. Letters to the editor-in-chief of the journal who published the study, Medicine and Science in Sports and Exercise, were submitted by Anne B. Loucks, and Nancy I. Williams and Mary Jane De Souza (Loucks A. B., 2006; Williams \& De Souza, 2006).

Williams and De Souza (2006) argued that definitions for the female athlete triad criteria used in this study resulted in overestimating the occurrence of the triad in controls 
but underestimating occurrence in athletes. For example, Williams and De Souza pointed out that Torstveit and Sundgot-Borgen (2005) used a narrow definition of disordered eating because it did not contain inadvertently failing to match caloric intake to energy expended. In addition, they stated that errors were made in the definition of short luteal phase. Furthermore, criteria for low bone mineral density were used that are not included in the requirements for an osteoporosis diagnosis within premenopausal women and adolescents (Williams \& De Souza, 2006).

Loucks (2006) also found issue with the Torstveit and Sundgot-Borgen (2005) article in that she thought occurrence of the female athlete triad could not be established based on the data collected for the study. For example, Loucks indicated that Torstveit and Sundgot-Borgen did not determine caloric intake, energy expenditure, or hormone levels. In addition, Loucks stated that more than one bone density measurement should have been taken in order to assess if there was a decrease in Z-scores.

Torstveit and Sundgot-Borgen (2006) wrote a response to both of these letters to the editor where criticism of their study was addressed. According to the 1997 ACSM position stand, the female athlete triad not only occurs in athletes but also physically active females not competing in athletics (Otis et al., 1997). Torstveit and SundgotBorgen responded that results of their study support this statement.

Drive for thinness score is a possible identifier for risk of the female athlete triad in that it is an indicator of energy deficiency (De Souza, Hontscharuk, Olmsted, Kerr, \& Williams, 2007). This study not only found an association between a high drive for thinness and energy deficiency but also menstrual irregularities. Therefore, results of this 
study suggested a high drive for thinness score may aid in early detection before clinical conditions emerge (De Souza, et al., 2007).

Preparticipation evaluation (PPE) forms are intended to identify female collegiate athletes at risk of the female athlete triad, however, a recent study indicated that PPE forms used by NCAA Division I universities may be ineffective (Mencias, Noon, \& Hoch, 2012). The Female Athlete Triad Coalition recommends 12 questions to be on the PPE forms in order to screen for the female athlete triad, but more than half of the universities in this study used PPE forms with less than $50 \%$ of these recommendations. In addition, preparticipation screening was required at all the universities participating in this study but only $32 \%$ required annual screening. Therefore, these results indicated that returning athletes at risk of the female athlete triad may not be identified (Mencias et al., 2012).

\section{Prevention of the Female Athlete Triad}

Education is crucial to the prevention of the female athlete triad and involves not only the athlete but also parents, coaches, athletic trainers, and physicians (Sanborn, Horea, Siemers, \& Dieringer, 2000; Staurowsky et al., 2009). However, a study by Beals (2003) indicated that although colleges may have female athlete triad education available, many do not make this education a requirement. The survey results from 138 NCAA Division I schools revealed that $73 \%$ of the schools provided education to athletes but it was only mandatory at $41 \%$ of the schools. Furthermore, $61 \%$ of the schools provided education to coaches but less than $28 \%$ of the schools made it a requirement (Beals, 2003). 
Athletes should be educated about the importance of optimal nutrition intake in order to maintain energy balance and prevent the occurrence of the female athlete triad (Staurowsky et al., 2009). The ACSM recommends educating athletes with low energy availability and/or menstrual disorders about the negative effects on bone health (i.e., failure to achieve peak bone mass, decreased BMD, stress fractures, and osteoporosis) (Nattiv et al., 2007). Education is important since "BMD loss is a silent process so an athlete may not be aware of an issue until a stress fracture occurs or they are diagnosed with osteopenia" (Burrows \& Bird, 2000, p. 289).

According to Beals, Brey, \& Gonyou (1999), prevention of the female athlete triad can be categorized as primary, secondary and tertiary prevention. The goal of primary prevention would be to educate athletes about the importance of nutrition on health and performance. Secondary prevention would focus on identifying athletes at risk of the female athlete triad and tertiary prevention involves treating athletes who have developed any of the disorders of the triad (Beals et al., 1999).

\section{Treatment of the Female Athlete Triad}

Treatment of the female athlete triad involves increasing energy intake and/or reducing exercise energy expenditure without causing a drastic change in weight (Manore et al., 2007). Restoring energy availability leads to resumption of the menstrual cycle (Kopp-Woodroffe, Manore, Dueck, Skinner, \& Matt, 1999) which will improve bone mineral density (Nattiv et al., 2007). Treatment of the female athlete triad involves nutrition counseling, but athletes with disordered eating or eating disorders need additional psychotherapy (Nattiv et al., 2007). 
Treatment of the female athlete triad is considered a team effort which includes: physicians, registered dietitians, mental health counselors, athletic trainers, and to a lesser extent, the coach (Sanborn et al., 2000). However, a study by Troy, Hoch, and Stavrakos (2006) indicated that some of these team members not only did not know the three components of the triad, but also felt uncomfortable treating the triad. Survey results revealed that only $48 \%$ of the physicians, $43 \%$ of the physical therapists, and $32 \%$ of the medical students participating in the survey were able to name the three components of the triad. In addition, only $38 \%$ of athletic trainers and $8 \%$ of the coaches were able to name the three components. Results of the study revealed that only $31 \%$ of the physicians, $32 \%$ of the medical students, $29 \%$ of the physical therapists, and $26 \%$ of the athletic trainers reported screening for the triad. Furthermore, $11 \%$ of the physicians, $0 \%$ of the medical students, $14 \%$ of the physical therapists, and $18 \%$ of the athletic trainers reported that they felt comfortable treating the triad (Troy et al., 2006).

Another survey involving clinicians found that $80 \%$ of the survey participants thought the evaluation and treatment guidelines for athletic amenorrhea were lacking (Carlson, Curtis, \& Halpern-Felsher, 2007). Survey results indicated that clinicians thought better guidelines were needed for assessment, bone density scans, estrogen therapy, and other types of treatments (Carlson et al., 2007).

\section{Dietary Intake}

\section{Recommendations for Athletic Performance}

Athletes need to consume appropriate amounts of energy and macronutrients in order to support their athletic performance (ACSM, ADA, \& Dietitians of Canada, 2009). 
Optimal amounts of carbohydrates are needed to fuel their performance and to replenish glycogen (ACSM, ADA, \& Dietitians of Canada, 2009). In addition, adequate protein will build muscle and repair any damage (ACSM, ADA, \& Dietitians of Canada, 2009). Recommended energy intakes for athletes are: (a) 30-45 $\mathrm{kcal} / \mathrm{kg} \mathrm{FFM}^{-1}$ per day for athletes who want to lose weight, (b) approximately $45 \mathrm{kcal} / \mathrm{kg} \mathrm{FFM}^{-1}$ per day for athletes who want to maintain their current weight, and (c) more than $45 \mathrm{kcal} / \mathrm{kg} \mathrm{FFM}^{-1}$ per day for growth and carbohydrate loading (Manore et al., 2007).

The ACSM, ADA, and Dietitians of Canada released a position stand in 2009 detailing the recommendations for athletic performance which vary in range based upon the type of sport, gender, and body weight (ACSM, ADA, \& Dietitians of Canada, 2007). The recommendations in this position stand are: (a) $6-10 \mathrm{~g} / \mathrm{kg}^{-1}$ body weight per day of carbohydrates, (b) $1.2-1.7 \mathrm{~g} / \mathrm{kg}^{-1}$ per body weight per day of protein, and (c) $20 \%-35 \%$ of total calories from fat. Athletes should also consume 30-60 grams of carbohydrates every hour of exercise along with adequate fluid consumption. In addition, it is recommended that athletes replace fluid loss with 16-24 fluid ounces per pound lost during performance. For recovery it is recommended that athletes consume $1.0-1.5 \mathrm{~g} / \mathrm{kg}^{-1}$ body weight of carbohydrates within 30 minutes after activity and again in two hours for an additional four to six hours (ACSM, ADA, \& Dietitians of Canada, 2009).

\section{Dietary Intake of Adolescent Athletes}

A study by Cupisti, D'Alessandro, Castrogiovanni, Barale, \& Morelli (2002) examined the dietary intake of adolescent athletes and nonathletes. Results indicated that both groups consumed below the estimated energy requirements and what was 
recommended for their age group. However, there was greater difference in actual intake versus estimated intake in the athletes. The athletes consumed less fat but more carbohydrates than the nonathletes. In addition, the athletes consumed more fiber, iron, and vitamin A than the nonathletes. Furthermore, athletes consumed more calories at breakfast than the nonathletes. Cupisti et al. (2002) reported that the results indicated sports can have a positive effect on dietary intake.

\section{Dietary Intake of Female Collegiate Athletes}

Studies have shown that female collegiate athletes have inadequate dietary intake (Hoogenboom et al., 2009; Shriver et al., 2013; Valliant et al., 2012). Hoogenboom et al. (2009) reported that female collegiate swimmers failed to consume the RDA for carbohydrates, proteins, and fats. Furthermore, a 24-hour food recall revealed skipped meals and low energy intake. A study involving female collegiate volleyball players had similar findings. A three day food log indicated players were skipping meals and not eating the recommended amount of calories and macronutrients (Valliant et al., 2012). A recent study by Shriver et al. (2013) looked at the dietary intakes and eating habits of female collegiate athletes from various sports such as soccer, basketball, cross-country, and track and field. Analysis of a three day food log and a twenty-four hour recall revealed that the athletes' intake fell within the Acceptable Macronutrient Distribution Ranges (AMDR) but energy and carbohydrate intake fell below the sports nutrition guidelines (Shriver et al., 2012). This study also indicated that breakfast was often skipped by female collegiate athletes. Despite not meeting the recommendations for energy and macronutrients, some female collegiate athletes expressed a desire to lose 
weight (Shriver et al., 2013; Valliant et al., 2012). A study by Hinton, Sanford, Davidson, Yakushko, \& Beck (2004) found that sixty-two percent of female collegiate athletes wanted to lose weight and were willing to sacrifice energy and macronutrient intakes in order to achieve at least a five pound loss.

\section{Nutrition Knowledge}

\section{General Nutrition Knowledge}

A study by Wardle, Parmenter, and Waller (2000) suggests that nutrition knowledge influences fruit, vegetable, and fat intake. Results of the study which included 1,040 randomly selected adults indicated that participants with higher nutrition knowledge scores consumed more fruits and vegetables and less fat than participants with lower nutrition knowledge scores. These results suggest that nutrition knowledge may be a key factor in improving dietary intake (Wardle, Parmenter, \& Waller, 2000).

\section{Nutrition Knowledge of all Athletes}

A study by Harrison, Hopkins, MacFarlane, and Worsley (1991) indicated that elite athletes demonstrated greater nutrition knowledge than nonelite athletes. Results of the study also revealed that females answered more questions correctly although it was not statistically significant (Harrison et al., 1991). Another study on nutrition knowledge indicated there was no difference in the mean nutrition knowledge score among female and male collegiate athletes (Rosenbloom \& Jonnalagadda, 2002). Results of the study revealed that athletes had a high level of knowledge regarding hydration and performance, but knowledge of macronutrients and performance were lacking. Furthermore, $67 \%$ of the male athletes and $53 \%$ of the female athletes agreed with a 
statement that vitamins and minerals increased energy (Rosenbloom \& Jonnalagadda, 2002).

Other studies have examined nutrition knowledge of athletes and nonathletic controls (Barr, 1987; Frederick \& Hawkins, 1992; Raymond-Barker, Petroczi, \& Quested, 2007). Raymond-Barker et al., (2007) used The General Nutrition Knowledge Questionnaire (GNKQ) to assess nutrition knowledge among athletes and nonathletes. In addition, nutrition knowledge of athletes considered at risk of the female athlete triad was compared to athletes not at risk. The athlete group, 48 endurance athletes and 11 trampoline gymnasts, were selected for the study because these athletes are considered at risk of the female athlete triad. Results of the study indicated that athletes have greater nutrition knowledge than nonathletes, but there was no difference in nutrition knowledge among athletes at risk versus not at risk of the female athlete triad (Raymond-Barker et al., 2007). A similar study by Barr (1987) assessed the nutrition knowledge of athletes and nonathletes at the university level. Unlike the Raymond-Barker et al. (2007) study, the athletes in this study demonstrated nutrition knowledge comparable to that of nonathletes. Furthermore, greater knowledge of general nutrition versus sports nutrition was indicated for both the athletes and the nonathletes in this study (Barr, 1987). Another study involving athletes and nonathletes found different results than the Barr (1987) and Raymond-Barker et al. (2007) studies. Frederick and Hawkins (1992) assessed the nutrition knowledge of female collegiate athletes, nonathletes and postmenopausal women. Results of the study indicated that nonathletes had greater nutrition knowledge than athletes and postmenopausal women. However, the nonathlete 
group consisted of students who were food and nutrition majors (Frederick \& Hawkins, 1992).

\section{Nutrition Knowledge of Female Collegiate Athletes}

A number of studies have indicated nutrition knowledge among female collegiate athletes is lacking. Zawila et al. (2003) used a nutritional questionnaire to assess the knowledge of female collegiate cross-country runners and found that they lack the nutrition knowledge needed to maintain optimal health. A study on the nutrition knowledge of female collegiate softball players found that only fifty-seven percent of the questions on a nutrition survey were answered correctly (Hornstrom et al., 2011). Female collegiate swimmers were only able to demonstrate a fair amount of nutrition knowledge on a nutritional knowledge questionnaire (Hoogenboom et al., 2009). A sports nutrition knowledge survey indicated that female collegiate volleyball players were lacking in knowledge regarding weight control, dietary supplements, and general nutrition (Valliant et al., 2012). Another study indicated that female collegiate soccer players and swimmers were only able to score seventy percent on a nutrition knowledge assessment (Abood, Black, \& Birnbaum, 2004). This lack of nutrition knowledge is concerning since female collegiate athletes have problems applying their knowledge, although limited, to their dietary habits (Hoogenboom et al., 2009). For example, $90.59 \%$ of the female collegiate swimmers in the Hoogenboom et al. (2009) study failed to consume appropriate amounts of macronutrients despite being able to answer $71.75 \%$ of the nutrition survey questions correctly. 
A review by Heaney, O’Connor, Michael, Gifford, and Naughton (2011) suggested that there is a positive correlation between nutrition knowledge and dietary intake. This is consistent with the results of the study by Hornstrom et al. (2011) who found that female collegiate softball players with a low nutrition knowledge score had poorer dietary habits than those with a higher score. A study by Kunkel, Bell, and Luccia (2001) suggests that a nutrition education program increases the nutrition knowledge of female collegiate athletes. Further studies have shown that nutrition education not only improved nutrition knowledge but also the dietary intake of female collegiate athletes (Abood et al., 2004; Valliant et al., 2012). Nutrition education is important since many athletes may not understand the implications of nutrition on health and performance.

\section{Female Athlete Triad Knowledge}

There are limited studies on knowledge of the female athlete triad (Miller et al., 2012; Simpson et al., 1998). Miller et al. (2012) surveyed 180 female exercisers and found that only $10 \%$ were able to name the three components of the female athlete triad. In addition, only 54\% were aware of the connection between low energy availability and amenorrhea. Furthermore, only 54\% knew that menstrual dysfunction is a risk factor for poor bone health. Results of the study also indicated that $35 \%$ of female exercisers viewed irregular periods as a normal occurrence in active females. These results indicated female exercisers do not understand the connection between the three components of the female athlete triad (Miller et al., 2012).

A similar study examined knowledge and attitudes about the female athlete triad among female collegiate athletes (Simpson et al., 1998). Simpson et al. (1998) surveyed 
189 female collegiate athletes and found that only $35 \%$ were aware that amenorrhea is a risk factor for osteoporosis (Simpson et al., 1998). Turner and Bass (2001) reported a higher percent $(72 \%)$ of knowledge of the connection between amenorrhea and bone density on an osteoporosis knowledge questionnaire given to 114 female collegiate athletes. Simpson et al. reported that $49 \%$ of female collegiate athletes surveyed thought missing a period was okay. Results of this study indicated that female collegiate athletes do not understand how amenorrhea negatively impacts their bone health (Simpson et al., 199).

This lack of knowledge about the female athlete triad and the three components has also been shown among collegiate coaches. Only $43 \%$ of 91 collegiate coaches were able to identify the three components of the female athlete triad even though $64 \%$ answered "yes" to having heard of it (Pantano, 2006). Survey results also indicated that $24 \%$ of coaches thought menstrual irregularities were a normal occurrence among active females.

\section{Educational Interventions}

\section{Intervention with College Women}

Koszweski, Newell, and Higgins (1990) examined the effect of a nutrition education program on the knowledge and eating attitudes and behaviors of university students recruited from one university and two colleges. Results of the study indicated that the nutrition education program had no effect on the knowledge of the experimental groups or the control groups. However, participants of the study were nutrition, health, and physical education majors which may explain why there was no difference in the 
pretest and posttest scores. Retest scores for the experimental groups from the two colleges indicated that the nutrition education program was effective at improving eating attitudes and behavior.

\section{Interventions with Collegiate Athletes}

Numerous studies have indicated educational interventions are successful in eliciting positive changes in female collegiate athletes. Educational interventions have been shown to be effective at improving the nutrition knowledge of female collegiate athletes (Abood et al., 2004; Collison, Kuczmarski, \& Vickery, 1996; Kunkel et al., 2001). Other studies have indicated that educational interventions are effective at reducing risk factors for eating disorders among female collegiate athletes (Abood \& Black, 2000; Becker, McDaniel, Bull, Powell, \& McIntyre, 2012).

Collison et al. (1996) compared the effect of a nutrition education program on nutrition knowledge and attitudes of female collegiate athletes versus nonathlete female college students. Diet analysis was used to test the effectiveness of a nutrition education program on energy, macronutrient, iron, and calcium intakes. Posttest results indicated that the education intervention was effective at increasing nutrition knowledge and attitudes among female athletes. An insignificant increase in nutrition knowledge and attitudes was shown among the nonathlete group. However, the authors acknowledge that the pretest scores for the nonathlete group were higher which may be a result of inclusion of nutrition majors $(28 \%)$ in this group. The educational intervention had no effect on dietary intake for either group. 
A similar study by Kunkel et al. (2001) found that female collegiate athletes who participated in a peer nutrition education program were able to increase their scores on general nutrition and sports nutrition knowledge questions. This study involved 32 female athletes who were divided into groups of eight and then assigned to one peer educator (female nutrition students). The athletes met with their peer educator once per week either as a group or individually, however, the authors do not mention how many weeks the educational program lasted.

An additional study by Abood et al. (2004) found that an eight week educational intervention was effective at improving nutrition knowledge, dietary intake, and increasing self-confidence in food choices among a female collegiate soccer team. This study used a pretest-posttest design with a women's soccer team as the experimental group and a women's swim team as the control group. The experimental group received an eight week educational intervention but the control group did not. However, they did meet in a different facility at the same time as the experimental group. Posttest results revealed significant improvement in nutrition knowledge, dietary intake, and confidence in food choice selection for the experimental group, the soccer team.

In addition to nutrition, educational interventions have also been used in studies involving female collegiate athletes and eating disorders. A study by Abood and Black (2000) indicated that an eight week educational intervention is effective at decreasing drive for thinness and body dissatisfaction which are characteristics of eating disorders. These are subscales of the Eating Disorder Inventory-2 (EDI-2) which was used as part of the pretests and posttests along with the Sport Competition Anxiety Test (SCAT), 
Rosenberg Self-Esteem Test (RSET), Self-Rating Anxiety Scale (SAS), and a nutrition questionnaire. The drive for thinness subscale measures an individual's intense fear of weight gain and preoccupation with dieting and weight. The body dissatisfaction subscale measures dissatisfaction with body shape and size.

This study consisted of 70 female collegiate athletes with 35 serving as the control group and 35 serving as the experimental group (Abood \& Black, 2000). The participants were given the same pretest and posttest, but the experimental group alone received an eight week educational intervention. Although the control group did not receive an educational intervention, they did meet at the same time as the experimental group, but in a different building. Posttest results revealed the experimental group had decreased scores on the drive for thinness and body dissatisfaction subscales.

A similar study by Becker et al. (2012) examined the effects of peer-led interventions on risks factors for eating disorders among female collegiate athletes. For this study, female collegiate athletes were randomly assigned to two different intervention groups, athlete-modified dissonance prevention (AM-DBP) and athletemodified healthy weight intervention (AM-HWI). The interventions, conducted by athletes who were trained to be peer leaders, were held one time per week for three weeks. Surveys were given before and after the interventions and also at a six week and one year follow-up. Results of this study indicated that eating disorder risk factors decreased after participation in both intervention groups. Interestingly, the authors report that seven of the athletes approached the athletic trainer about possibly having the female athlete triad. 
The previous studies demonstrate the effectiveness of interventions within the female collegiate athlete population. Therefore, an educational intervention may have promising results when applied to female athlete triad knowledge. An intervention for female collegiate athletes may lead to increased knowledge of the female athlete triad and a decrease in the risk for the triad. 


\section{CHAPTER III}

\section{METHODS}

The purpose of this study was to test the effectiveness of educational interventions for female collegiate athletes on knowledge of the female athlete triad. The aims of the study were: (a) to measure the knowledge of female collegiate athletes about the female athlete triad; (b) to educate female collegiate athletes about the triad, making use of an educational presentation and handout; and (c) to retest female collegiate athletes' knowledge in order to evaluate the effectiveness of an educational intervention. This investigation benefits research on the female athlete triad because there are limited studies on female collegiate athletes' knowledge of the triad and to date, there has not been a study on the effectiveness of an educational intervention.

Research questions addressed in this study included:

1. What is the status of female athlete triad knowledge among female collegiate athletes?

2. Does an educational intervention on the female athlete triad improve female athlete triad knowledge among female collegiate athletes?

\section{Research Design}

This experimental research study used a four group pretest-posttest design. The effectiveness of an educational intervention was measured by retesting all four groups. The independent variable was the educational intervention and the dependent variable was athletes' knowledge about the female athlete triad. 


\section{Participants}

The population included all NCAA, Division I female collegiate athletes. The subject sample in this study was selected as a convenience sample from a Midwestern university in the Mid-American Conference (MAC). The experimental and control groups were selected at random. Female collegiate athletes from the basketball, soccer, softball, and track and field teams participated in the study with each team representing either an experimental group or the control group. Exclusion criteria for this study were diagnosis of the female athlete triad or diagnosis of an eating disorder.

\section{Intervention}

The four groups were classified as presentation only (PO), handout only (HO), presentation and handout $(\mathrm{PH})$, and control $(\mathrm{CT})$. The $\mathrm{PO}$ group received an educational intervention session in the form of a PowerPoint presentation (Appendix A). This 15 minute presentation was developed after an extensive review of the literature related to the female athlete triad. It focused on defining the female athlete triad and how the three components are interconnected. The presentation also covered risk factors and signs and symptoms of the female athlete triad. Special attention was given to the importance of optimal nutrition intake in order to prevent the occurrence of the triad. The presentation also included a list of people an athlete can approach if she is experiencing any signs or symptoms of the female athlete triad.

The HO group received an educational handout (Appendix B) reproduced with permission from The Female Athlete Triad Coalition (www.femaleathletetriad.org) that provided an overview of the Triad similar to the educational presentation. The PH group 
received both the educational presentation and handout. The CT group received no intervention. These interventions were intended to improve knowledge about the female athlete triad.

\section{Measurement Instrument}

The measurement instrument in this study was a Triad Knowledge Questionnaire (TKQ) developed by the author and thesis advisor (Appendix C). The content of the TKQ was based on information obtained from an exhaustive review of the literature. This TKQ included a demographic section, a knowledge section, and an unscored section. The first part of the TKQ related to background information such as birth date, school rank, and sport. The birth date was used to match the pretest with the posttest only and not for identifying purposes. Other demographic information in the TKQ included major, nutrition courses taken, and diagnosis of an eating disorder or female athlete triad.

The portion of the TKQ that assessed knowledge of the female athlete triad had a possible score of 27. One of the knowledge questions involved identification of the triad components, one related to the signs/symptoms of the triad and another question was about the treatment. The component and signs/symptoms questions were worth six and 11 points, respectively. For these two questions each correct answer was worth one point and each incorrect answer that was not selected was worth one point. For example, the

component question had three incorrect responses in addition to the three components of the female athlete triad. If a participant correctly selected the three components and did not select the three incorrect responses then six points were earned. The treatment 
question was worth one point if it was correctly answered. There were also nine true or false questions related to the cause, the health outcome, and the risk of the female athlete triad worth nine points if correctly answered.

The remainder of the TKQ included two unscored components one of which was a question about the screening process for the female athlete triad which identified if athletes were aware of the process at their university. In addition, the last question asked the participants to rank order the most effective to least effective resource for student athletes, regarding triad information and support.

\section{Procedure}

Approval for this study was granted by the Institutional Review Board (IRB) at Kent State University. An email (Appendix D) explaining the research study was sent to the coaches of all the female collegiate athletic teams asking if their team would be interested in participating. Coaches from five teams responded to the email but one team was unable to participate due to the time commitment. The four teams that chose to participate in the study were randomly selected to serve as the control group and experimental groups. Meetings were scheduled for both the pretest and posttest based on each team's availability. These meetings were held separately for each of the four teams. The first five to ten minutes of each of these meetings involved introduction of the author and thesis advisor with an explanation of the study. This included informing the intervention groups of whether they would be receiving a presentation, handout, or both. Each team was given instructions on how to proceed if they chose to participate in the study which included a review of the consent form (Appendix E). They were advised 
that participation was voluntary and instructed to turn in a blank consent form and TKQ if they did not want to participate. The consent form and TKQ were distributed following this detailed explanation with instructions to place them in the separate manila envelopes provided upon completion. After completing the TKQ pretest, each team received the randomly assigned interventions and the control was dismissed.

All four teams were retested separately in the week following their initial test. Each of the teams was reminded again that participation was voluntary and that they could place a blank TKQ in the manila envelope. The teams representing the intervention groups were thanked for their participation and dismissed after completing the TKQ. As a courtesy, the control group was given the answers to the TKQ after completing the posttest along with a question and answer session since they did not receive any education.

\section{Data Analysis}

Data collected was analyzed using Statistical Package for the Social Sciences (SPSS), Version 20.0. Descriptive statistics were used to analyze participant characteristics. A one-way Analysis of Variance (ANOVA) was used to determine if there were mean differences at posttest between the four groups on knowledge of the female athlete triad. An ANOVA was also used to determine if each group improved in knowledge of the female athlete triad from pretest to posttest. A significance level of $p<$ .05 was set. Frequency distributions were used to report participant responses to the screening process question and the rank order of available resources. 


\section{CHAPTER IV \\ JOURNAL ARTICLE}

Introduction

Over the past three decades the number of women participating in The National Collegiate Athletic Association (NCAA) has increased from approximately 74,239 to 198,103, a 267\% increase (National Collegiate Athletic Association, 2012). Optimal nutrition intake is needed to fuel this physical activity and to maximize performance and recovery (American College of Sports Medicine, American Dietetic Association, \& Dietitians of Canada, 2009). However, female athletes may intentionally or unintentionally restrict their caloric intake or over train in an effort to excel at their sport or to achieve a lean physique (Pantano, 2006). This may result in an energy deficit which puts these female athletes at risk of the female athlete triad, also referred to as the triad.

The female athlete triad is a syndrome that consists of three interconnected components: energy availability, menstrual function, and bone mineral density, which encompasses a range from optimal health to disease (Nattiv et al., 2007). At the severest end of the spectrum, clinical conditions including eating disorders, functional hypothalamic amenorrhea (absence of menses), and osteoporosis (low bone density) may be present (Nattiv et al., 2007).

Education is essential to the prevention of the female athlete triad (Miller et al., 2012; Nattiv et al., 2007; Staurowsky et al., 2009). Female athletes who do not understand the connection between the components of the triad may not realize they have the syndrome until they have a stress fracture, a common first symptom (Sundgot-Borgen 
\& Torstveit, 2003). A lack of outward signs could indicate that female athletes may disregard the severity of low energy availability and amenorrhea. This supports the importance of educating female athletes about the triad in order to prevent its occurrence.

A recent study by Miller et al. (2012) indicated that female exercisers lack knowledge about the three components of the female athlete triad and how they are interconnected. The female athlete triad is of concern because the components, occurring in combination or separately, not only affects physical performance but can lead to morbidity and mortality (Otis et al., 1997). Increasing knowledge of the female athlete triad through education is considered essential to its prevention (Sanborn et al., 2000; Staurowsky et al., 2009). However, a problem among some NCAA Division I schools is that female athlete triad education is not a requirement, although educational programs are available at some of these institutions (Beals, 2003). Furthermore, not all NCAA schools have a registered dietitian on staff (Karpinski, 2012) who can educate athletes about the importance of fueling their bodies in order to maintain energy balance.

Only two studies have addressed knowledge of the female athlete triad among female exercisers and athletes (Miller et al., 2012; Simpson et al., 1998). In addition to knowledge, surveys used in these studies focused on attitudes and behaviors about the female athlete triad and its components. However, neither of these studies used a questionnaire to specifically measure knowledge of the female athlete triad. Furthermore, to date, no one has examined if an educational intervention can improve knowledge of the female athlete triad. Therefore, it is imperative to determine the impact of education on female collegiate athletes and their knowledge of the female athlete triad. 
The purpose of this study was to assess if an educational intervention would improve knowledge of the female athlete triad among female collegiate athletes at a Midwestern NCAA affiliated university. The aims of the study were: (a) to measure the knowledge of female collegiate athletes about the female athlete triad; (b) to educate female collegiate athletes about the triad, making use of an educational presentation and handout; and (c) to retest female collegiate athletes' knowledge in order to evaluate the effectiveness of an educational intervention.

\section{Methods}

\section{Procedure}

A recruitment email was sent to the coaches of all the female athletic teams. The four teams that chose to participate were randomly assigned to groups classified as presentation only $(\mathrm{PO})$, handout only $(\mathrm{HO})$, presentation and handout $(\mathrm{PH})$, and control (CT). Meetings with each of the four teams were held separately and emphasis was placed on participation being voluntary. The TKQ with the consent form attached was distributed to each of the four teams. After completing the TKQ, the experimental groups received the randomly assigned interventions and the control was dismissed.

The PO group received an educational intervention session in the form of a PowerPoint presentation. The PowerPoint presentation focused on defining the female athlete triad and how the three components are interconnected. Special attention was given to the importance of optimal nutrition intake in order to prevent the occurrence of the triad. The HO group received an educational handout reproduced with permission from The Female Athlete Triad Coalition (www.femaleathletetriad.org) that provided an 
overview of the Triad similar to the educational presentation. The PH group received both the educational presentation and handout. The CT group received no intervention.

All four teams were retested separately in the week following the pretest. As a courtesy the control group was given the answers to the TKQ after completing the posttest along with a question and answer session since they did not receive any education.

\section{Measurement Instrument}

Athletes' knowledge of the female athlete triad was measured using a Triad Knowledge Questionnaire (TKQ). The TKQ consisted of a demographic section, a knowledge section, and an unscored section. Background information collected included birth date, school rank, and sport. The birth date was used to match the pretest with the posttest only and not for identifying purposes. Other demographic information collected included major, nutrition courses taken, and diagnosis of an eating disorder or female athlete triad.

Female athlete triad knowledge questions related to identification of the components, signs/symptoms, and treatment. The TKQ also included a true/false section about the cause, health outcome, and risk of the female athlete triad. The total possible knowledge score was 27 . The component and signs/symptoms questions were worth six and 11 points, respectively. For these two questions each correct answer was worth one point and each incorrect answer that was not selected was worth one point. For example, the component question had three incorrect responses in addition to the three components of the female athlete triad. If a participant correctly selected the three components and 
did not select the three incorrect responses then six points were earned. The treatment question was worth one point if it was correctly answered. The nine true or false questions were worth a total of nine points each.

The remainder of the TKQ included two unscored components one of which was a question about the screening process for the female athlete triad which identified if athletes were aware of the process at their university. In addition, the last question asked the participants to rank order the most effective to least effective resource for student athletes, regarding triad information and support.

\section{Participants}

NCAA Division I female collegiate athletes were selected as a convenience sample from a Midwestern university in the Mid-American Conference (MAC). The experimental and control groups were selected at random. Female collegiate athletes from the basketball, soccer, softball, and track and field teams participated in the study with each team representing either an experimental group or the control group. Exclusion criteria for this study were diagnosis of the female athlete triad or diagnosis of an eating disorder.

\section{Statistical Analysis}

Data collected was analyzed using Statistical Package for the Social Sciences (SPSS), Version 20.0. Descriptive statistics were used to analyze participant characteristics. A one-way Analysis of Variance (ANOVA) was used to determine if there were mean differences at posttest between the four groups on knowledge of the female athlete triad. An ANOVA was also used to determine if each group improved in 
knowledge of the female athlete triad from pretest to posttest. A significance level of $p<$ .05 was set. Frequency distributions were used to report participant responses to the screening process question and the rank order of available resources.

\section{Results}

Forty-nine of the 58 participants who agreed to participate in the study completed both the pretest and posttest. None of the participants met the exclusion criteria of a diagnosis of an eating disorder or the female athlete triad. One of the PO participants was excluded due to incomplete sections on the posttest. Eight of the HO participants were lost to attrition. The final sample consisted of $\mathrm{PO}(n=14), \mathrm{HO}(n=7), \mathrm{PH}(n=9)$, and CT $(n=19)$. Demographic information is included in Table 1. The average age of the female athletes who participated in the study was 19.61 years old. Demographic data collected indicated only $22 \%$ of the study participants had heard of the female athlete triad. Of the 49 participants who completed the entire study, 55\% had taken a nutrition course in college, $49 \%$ had a college course in which nutrition was a component, and $51 \%$ reported that nutrition was included in a high school course. Since the female athlete triad has to do with exercise and nutrition, it is reasonable to assume students who are nutrition or exercise science/physiology majors would have heard of it. There were nine exercise science or physiology majors in the study sample but no nutrition majors. 
Table 1

Demographic Characteristics of Division I Female Collegiate Athletes $(N=49)$

\begin{tabular}{|c|c|c|c|}
\hline \multicolumn{2}{|l|}{ Characteristic } & \multirow[t]{2}{*}{$n$} & \multirow[t]{2}{*}{$\%$} \\
\hline Intervention $\mathrm{G}$ & & & \\
\hline & Presentation Only & 14 & 29 \\
\hline & Handout Only & 7 & 14 \\
\hline & Presentation \& Handout & 9 & 18 \\
\hline & Control & 19 & 39 \\
\hline \multicolumn{4}{|l|}{ School Rank } \\
\hline & Freshman & 17 & 35 \\
\hline & Sophomore & 15 & 31 \\
\hline & Junior & 11 & 22 \\
\hline & Senior & 6 & 12 \\
\hline \multicolumn{4}{|c|}{ Nutrition Course } \\
\hline & Yes & 27 & 55 \\
\hline & No & 22 & 45 \\
\hline \multicolumn{4}{|c|}{ Nutrition Component } \\
\hline & Yes & 24 & 49 \\
\hline & No & 21 & 43 \\
\hline & Left Blank & 4 & 8 \\
\hline \multicolumn{4}{|l|}{ HS Nutrition } \\
\hline & Yes & 25 & 51 \\
\hline & No & 22 & 45 \\
\hline & Left Blank & 2 & 4 \\
\hline \multicolumn{4}{|l|}{ Heard of Triad } \\
\hline & Yes & 11 & 22 \\
\hline & No & 38 & 78 \\
\hline
\end{tabular}


Table 2 includes the mean TKQ scores and standard deviations for both the pretest and posttest. The mean knowledge scores for all of the intervention groups increased pretest to posttest and the control remained the same. The results of a repeated measures ANOVA indicated a significant improvement $(F=53.09, p<.001)$ between pretest and posttest scores (Figure 1). Furthermore, there was a significant interaction between pretest and posttest and group $(F=20.16, p<.001)$. The PO group had a higher mean posttest score $(20.86 \pm 1.88)$ than the mean pretest score $(16.79 \pm 3.49)$. The HO group also had an increase in mean score from pretest $(15.29 \pm 4.99)$ to posttest $(17.86 \pm$ 4.60). The PH group showed the most improvement with mean pretest scores of $6.44 \pm$ 4.98 compared to the mean posttest score of $21.33 \pm 2.87$. The mean scores at pretest and posttest remained the same for the CT group, $11.26 \pm 8.73$ and $11.21 \pm 8.54$, respectively. Table 2

Means and Standard Deviations of Triad Knowledge Questionnaire Scores in Division I Female Collegiate Athletes $(N=49)$

\begin{tabular}{lrl}
\hline Intervention Group & \multicolumn{1}{l}{ Pretest } & Posttest \\
\hline & $16.79 \pm 3.49^{*}$ & \\
Presentation Only & $15.29 \pm 4.99^{*}$ & $20.86 \pm 1.88^{*}$ \\
Handout Only & $6.44 \pm 4.98^{*}$ & $17.86 \pm 4.60^{*}$ \\
Presentation \& Handout & $11.26 \pm 8.73$ & $21.33 \pm 2.87^{*}$ \\
Control & $12.53 \pm 7.29$ & $11.21 \pm 8.54$ \\
Total & & $16.78 \pm 7.32$ \\
\hline
\end{tabular}

*Statistically significant improvement in scores $(p<.001)$. 


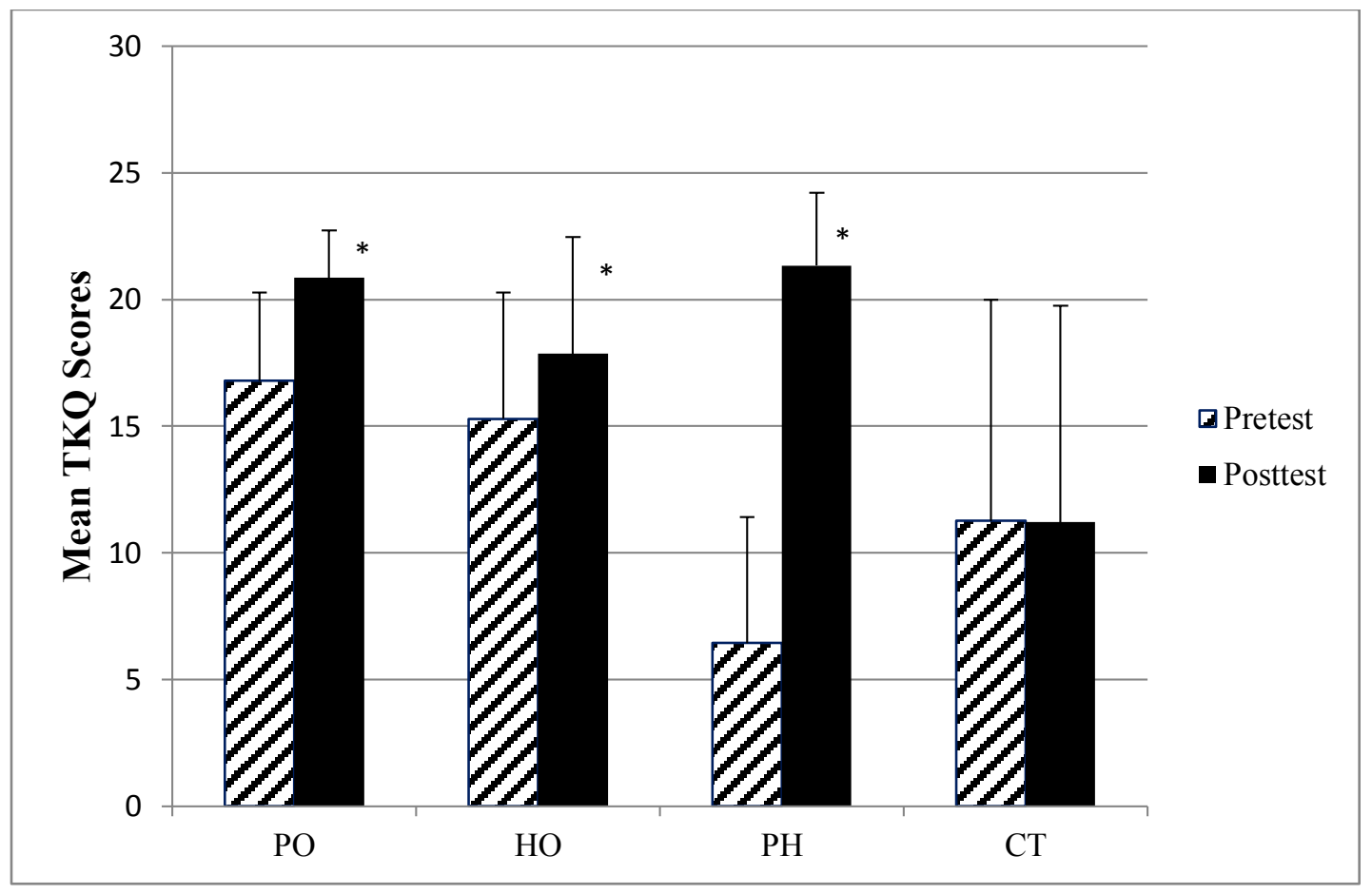

Figure 1. Mean Triad Knowledge Questionnaire scores from pretest to posttest by group $(N=49) . \mathrm{PO}=$ Presentation Only; $\mathrm{HO}=$ Handout Only; $\mathrm{PH}=$ Presentation $\&$ Handout; $\mathrm{CT}=$ Control. Error bars represent standard deviations. * Significant improvement in scores $(p<.001)$.

There was also a significant difference $(F=9.83, p<.001)$ between groups on TKQ posttest performance. Tukey post-hoc comparisons of the four groups indicate that there was a significant difference between the PO and CT groups $(p<.001)$, and PH and CT groups $(p<.001)$ (Figure 2$)$. The PH group slightly outperformed the PO group on the posttest. These groups were followed by the $\mathrm{HO}$ and $\mathrm{CT}$ groups in performance respectively. 


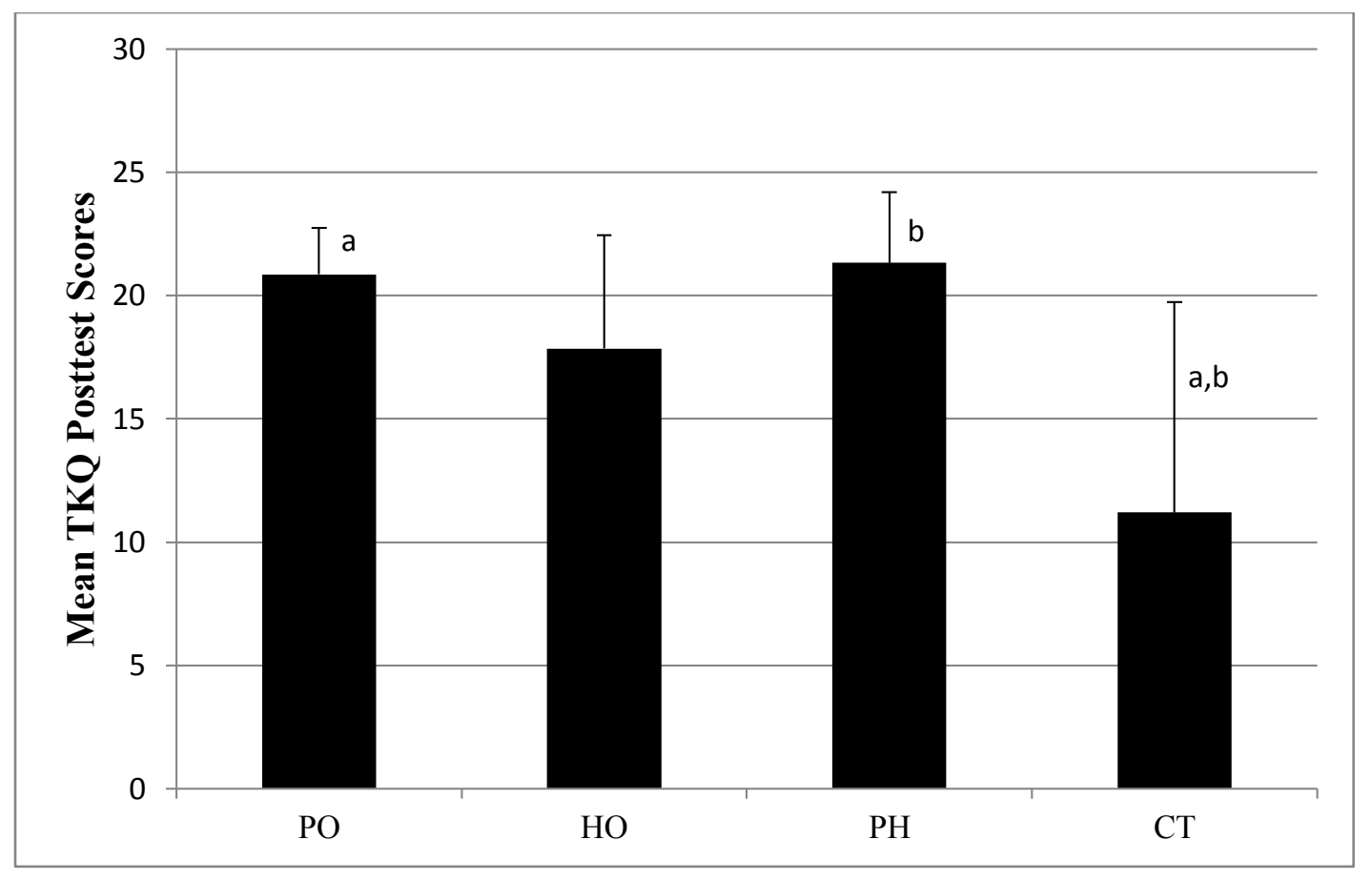

Figure 2. Triad Knowledge Questionnaire performance at posttest. PO = Presentation Only; $\mathrm{HO}=$ Handout Only; $\mathrm{PH}=$ Presentation \& Handout; $\mathrm{CT}=$ Control. Error bars represent standard deviations. ${ }^{a}$ Significant difference between PO and CT $(p<.001)$. ${ }^{\mathrm{b}}$ Significant difference between PH and CT $(p<.001)$.

The component question on the TKQ was analyzed separately for the sample as a whole. Only seven participants (14\%) could correctly identify all three components of the female athlete triad at pretest and $17(35 \%)$ at posttest. At pretest a higher number of participants were able to identify low energy availability and menstrual dysfunction as components versus bone loss. Thirty-five (71\%) of the participants selected low energy availability as a component at pretest and $42(86 \%)$ at posttest. Menstrual dysfunction was selected as a component by $34(69 \%)$ and $39(80 \%)$ of the participants at pretest and 
posttest, respectively. The greatest improvement was seen in identifying bone loss as a component with $17(35 \%)$ of the participants choosing it in the pretest and $34(69 \%)$ in the posttest.

Participants were asked when student-athletes are screened for the female athlete triad at their university. The frequency of responses at pretest and posttest are reported in Table 3. The majority of the female collegiate athletes participating in this study indicated they do not know when screening occurs.

Table 3

Frequency Distribution of Division I Female Collegiate Athletes' Responses to when Female Athlete Triad Screening Occurs at their University

$\begin{array}{cc}\begin{array}{c}\text { Pretest } \\ (n=46)^{\mathrm{a}}\end{array} & \text { Posttest } \\ (n=46)^{\mathrm{a}}\end{array}$

Incoming Freshman/Transfer

1

Preparticipation Examination $\quad 2 \quad 9$

Signs/Symptoms $\quad 6 \quad 4$

$\begin{array}{lll}\text { Never } & 7 & 10\end{array}$

$\begin{array}{lll}\text { Don't Know } & 30 & 21\end{array}$

${ }^{\text {a}}$ Three athletes excluded due to blank answers or checking more than one response.

A frequency distribution was used to determine which resources the participants indicated as the best to worst for information and support regarding the female athlete triad (Appendix F). The means and standard deviations of the rankings of available resources are listed in Table 4. 
Table 4

Means and Standard Deviations of Division I Female Collegiate Athletes' Rank of Available Resources for Female Athlete Triad Information and Support $(N=44)^{\text {a }}$

Resources $\quad M \pm S D$

Registered Dietitian/Nutritionist

$1.98 \pm 1.25$

Physician(MD)

$2.05 \pm 1.29$

Certified Athletic Trainer

$3.18 \pm 1.08$

Counselor

$4.93 \pm 1.55$

Internet

$5.43 \pm 2.21$

Coach

$5.64 \pm 1.37$

Parents

$5.64 \pm 1.84$

Teammates

$7.00 \pm 1.20$

Note. Rank $1=$ Best, $8=$ Worst.

${ }^{a}$ Five participants excluded due to missing or multiple use of ranking numbers.

\section{Discussion}

This study investigated the effectiveness of educational interventions for female collegiate athletes on knowledge of the female athlete triad. The results of this study demonstrated that there was an increase in female athlete triad knowledge scores from pretest to posttest. The results further reveal that female athlete triad knowledge is lacking in this sample of female collegiate athletes. However, the increase in TKQ scores attests to the effectiveness of an educational intervention for female collegiate athletes. Although this is the first educational intervention for the female athlete triad among female collegiate athletes, other studies have shown that interventions are effective at improving nutrition knowledge among this population (Abood et al., 2004; Collison et 
al., 1996; Kunkel et al., 2001). Female collegiate athletes appear to be receptive to education interventions. Therefore, athletic departments should invest time in educating their athletes in order to keep them healthy and thus, at their peak performance.

The results of the study support the hypothesis that female athlete triad knowledge would differ based on the intervention strategy. There was a significant difference between the four groups in TKQ scores. Mean TKQ scores increased for all three intervention groups with the $\mathrm{PH}$ group having the most significant increase from pretest to posttest. The PO group had the highest mean knowledge score for the pretest and the PH group had the highest mean score for the posttest. The combined mean and standard deviation for all three intervention groups: (a) PO, (b) HO, and (c) PH, increased from $13.33 \pm 6.23(49 \%)$ for the pretest to $20.30 \pm 3.19(75 \%)$ for the posttest, representing an improvement of $26 \%$. The two intervention groups that included a presentation, PO and $\mathrm{PH}$, had more of an improvement in scores than the HO group that only received a handout. This suggests that an intervention including a presentation is more effective than one without.

The findings of this study suggest female athlete triad knowledge is lacking among female collegiate athletes. The overall mean TKQ pretest score was $12.53 \pm 7.29$ and the mean posttest score was $16.78 \pm 7.32$ which is equivalent to a $46 \%$ and $62 \%$ respectively. Furthermore, only $22 \%$ of the study participants reported that they had heard of the female athlete triad at pretest. Of the 11 participants who answered "Yes" to having heard of the triad, eight of them were Exercise Physiology or Science majors. Three of the 11 participants having heard of the Triad were in the PO group, two in the 
HO group, and six in the CT group. Interestingly, the PH group who had the most significant increase in TKQ scores did not have any participants who had heard of the triad. These 11 participants who had heard of the triad had higher mean pretest scores $(16.91 \pm 6.82)$ than the 38 participants who had not heard of the triad $(11.26 \pm 7.00)$. However, their posttest scores remained about the same as the pretest, whereas those who had not heard of the triad had an increase.

A previous study found that female collegiate runners who had taken a nutrition course in college had higher nutrition knowledge scores versus those who had not (Zawila et al., 2003). Since the female athlete triad is often discussed in nutrition courses it is reasonable to assume that athletes who have taken a nutrition course would have higher scores. The 27 female collegiate athletes who had taken a collegiate nutrition course had a mean score of $14.26 \pm 6.69$ and $18.52 \pm 6.15$ on the pretest and posttest respectively, whereas the 22 athletes who did not had a mean score of $10.41 \pm 7.57$ on the pretest and $14.64 \pm 8.17$ on the posttest. Although these 27 athletes who had taken a nutrition course had better scores on the TKQ, only 11 reported they had heard of the female athlete triad. There appears to be some disconnect in what they have learned in their nutrition courses or in what they were reporting on the TKQ. However, it is possible that the female athlete triad was not covered in the nutrition courses these athletes have taken.

This study found that only approximately $14 \%$ of the sample at pretest could correctly identify all three components of the triad. This is similar to the findings of Miller et al. (2012) who reported that only $10 \%$ of their study participants were able to 
name the three components. Analysis of individual components revealed that low energy availability and menstrual dysfunction were recognized as components by more of the participants than bone loss. Seventy-one percent were able to identify low energy availability as a component and $69 \%$ menstrual dysfunction but only $35 \%$ were able to identify bone loss. Simpson et al. (1998) reported that only $35 \%$ of the female collegiate athletes in their study were aware that amenorrhea was a risk factor for osteoporosis. Miller et al. (2012) reported similar findings that only 54\% knew that menstrual dysfunction is a risk factor for poor bone health. In the present study, the lower number of participants selecting bone loss as a component may suggest that these athletes are also unaware of the link between the three components. Regardless, improvement was seen in the identification of all three components and within each of the components separately, with bone loss increasing the most at posttest. Younger females may not recognize bone loss as a component because they think of bone loss in relation to postmenopausal women. Turner and Bass (2001) reported that $77 \%$ of the female collegiate athletes in their study knew that bone loss accelerated after menopause. Their findings also revealed that only $43 \%$ of the athletes were worried about their risk of osteoporosis. Female collegiate athletes may believe that bone loss will not affect them until later in life so they are not able to make the connection to the female athlete triad.

The university at which these athletes compete screens incoming freshman and transfer students for the female athlete triad. Only one participant correctly identified this in the pretest and two participants in the posttest. It is concerning that seven (15\%) of the participants in the pretest and $10(22 \%)$ in the posttest answered "Never" to the screening 
question. Furthermore, thirty (65\%) of the participants selected that they did not know when screening occurred for the pretest and $21(46 \%)$ for the posttest. This suggests that the athletes at this university are not aware of what happens during their physical. Two observations can be made from these results. The first is that health care professionals and athletic departments are not explaining what is being assessed in these physicals. The second observation is that these athletes are not asking questions about their preparticipation examinations.

Female collegiate athletes in this study ranked registered dietitian (RD), physician (MD), and certified athletic trainer (ATC) as the top three best resources for information and support for the female athlete triad at pretest and posttest. A counselor was ranked as the fourth best resource followed by the internet, coach, and parents. Teammates were ranked as the worst resource for female athlete triad information and support.

Interestingly, previous studies have found parents, coaches, and teammates among the top sources for nutritional information among female collegiate athletes (Hoogenboom et al., 2009; Zawila et al., 2003). Since nutrition plays a key role in the female athlete triad it is important to note that the female collegiate athletes in this study ranked RD as one of the top resources of information about the triad.

\section{Limitations}

There were limitations to this study such as the small sample size. Email invitations to participate in the study were extended to the coaches of all female athletic teams on two separate occasions but only five teams showed interest. One of the teams could not participate due to the time commitment which left four teams. Coaches are 
only allowed a certain amount of hours with their team so it is understandable for them not to want to relinquish any of it to someone else. In addition, the sample size for each group was not equal which means the assumption of homogeneity was not met, but the significant difference between groups and across time cannot be overlooked. Another limitation of this study is that the measurement instrument was un-validated. Currently, there is not a survey that scores female athlete triad knowledge. Therefore, the TKQ used in this study is the first to be created.

\section{Applications}

The data suggests the importance of providing education to female collegiate athletes in order to increase their awareness of the female athlete triad. The findings of the study are beneficial to RDs, MDs, and ATCs since they were identified as top resources for female athlete triad information and support. These professionals should make sure they are well informed about the triad in order to offer education to female collegiate athletes. Furthermore, the data also indicates that female collegiate athletes do not fully understand all that is involved in their preparticipation examinations. Therefore, any health professional involved in these screenings should make an effort to explain what is being assessed during these physicals. Moreover, these professionals should take advantage of the opportunity during this screening to distribute educational materials such as a handout. Athletic departments should consider providing educational interventions to female collegiate athletes in order to prevent the occurrence of the female athlete triad. An RD or nutritionist could give a presentation to the athletes at the start of each season. With these professionals identified as top resources for female athlete triad 
information there is an opportunity for them to play a larger role in ensuring that these athletes are provided accurate information.

\section{Recommendations for Future Research}

Additional research is needed to test the effectiveness of an educational intervention for a larger sample of female collegiate athletes. The study should include female athletes from a variety of sports and across different geographical areas. In addition, future studies should expand upon the intervention types and timeframes used in this study in order to explore the best method.

\section{Conclusion}

The results of this study indicate that an educational intervention is effective at improving knowledge of the female athlete triad. Since education is considered essential to the prevention of the female athlete triad (Miller et al., 2012; Nattiv et al., 2007; Staurowsky et al., 2009) these findings suggest that female collegiate athletes may benefit from an educational program. The lack of knowledge of the female athlete triad demonstrated in this study attests to the need for educational interventions among the female collegiate athletic population. 


\section{APPENDICES}


APPENDIX A

\section{EDUCATIONAL PRESENTATION}




\section{Appendix A}

\section{Educational Presentation}

Slide 1

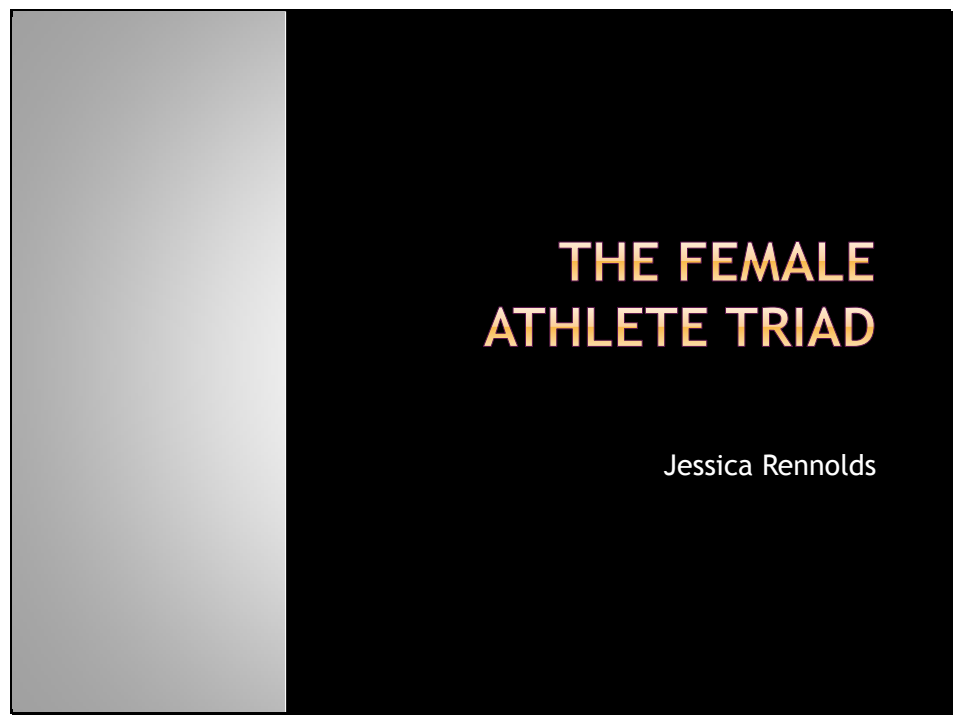

Slide 2

\section{WHAT IS IV?}

๑ Female Athlete Triad

= Composed of three components

Low energy availability

Menstrual dysfunction

Low bone mineral density

๑ Serious condition

- Components can lead to morbidity \& mortality 
Slide 3

\section{RISK OF THE FEMALE ATHLETE TRIAD}

๑ All physically active girls \& women are at risk

๑ Risk factors

- Participation in sports emphasizing a low body weight or lean physique

- Figure skating, gymnastics, ballet, distance running

- Participation in sports with weight checks - Wrestling, rowing, martial arts

- Participation in sports with revealing uniforms - Swimming, diving, volleyball

" Pressure to win

- Preoccupation with achieving/maintaining a certain body weight

Slide 4

\section{SIGNS \& SYMPTOMS}

- Irregular or absent menstrual cycles

- Always feeling tired \& fatigued

- Sleep disturbances

- Stress fractures \& frequent/recurrent injuries

- Regularly restricting food intake

- Drive for thinness

- Cold hands \& feet

- Restricting calories in an effort to improve performance or physical appearance 
Slide 5

Insufficient energy available for body
functions
$=$ Caloric intake - Calories burned = available
energy
Causes of low energy availability
$=$ Caloric intake is restricted
= Excessive energy expenditure
○ Burning more calories than consumed

Slide 6

\section{MENSTRUAL DYSFUNCTION}

\section{Amenorrhea}

- Delay to the start of the menstrual cycle

- Absence of menstrual cycle > 3 months

- Caused by low energy availability

- Disruption of hormones that regulate menstruation

$\odot$ Not a positive occurrence

- Detrimental to bone health 
Slide 7

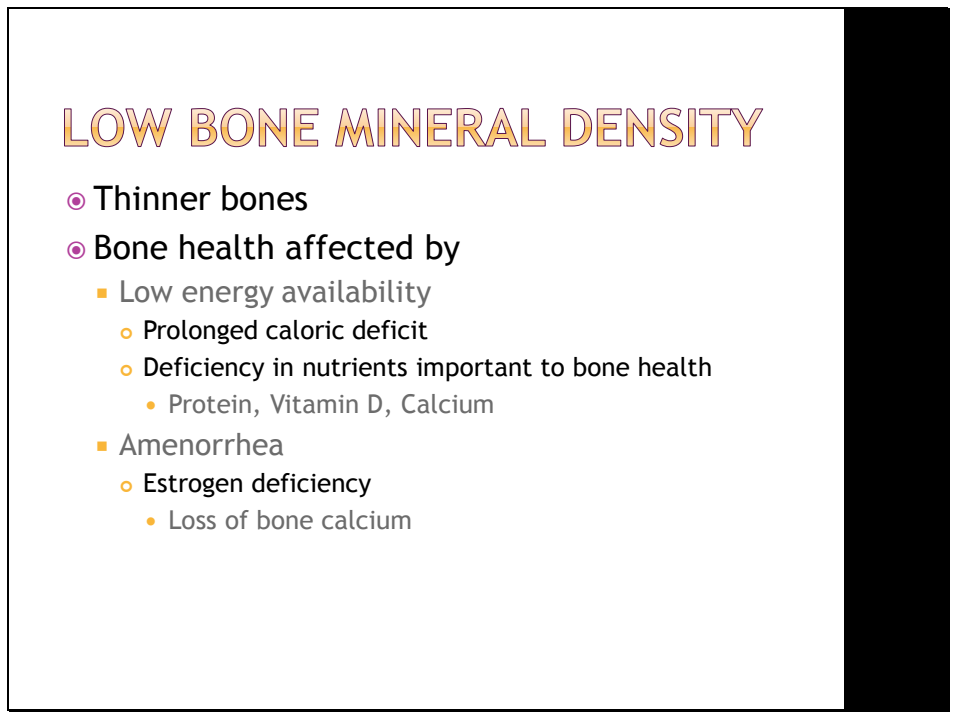

Slide 8

\section{WHY SHOULD YOU CARE?}

- Increased risk of stress fractures

- Brittle bones and mechanical stress of sports activity

- Stress fractures \& the healing process

- Bone takes time to heal - several months or longer

\section{Treatment}

- Rest with pain relievers

Time off from sport

- Slow reintroduction to sport

- May not be able to reach prior level of activity 
Slide 9

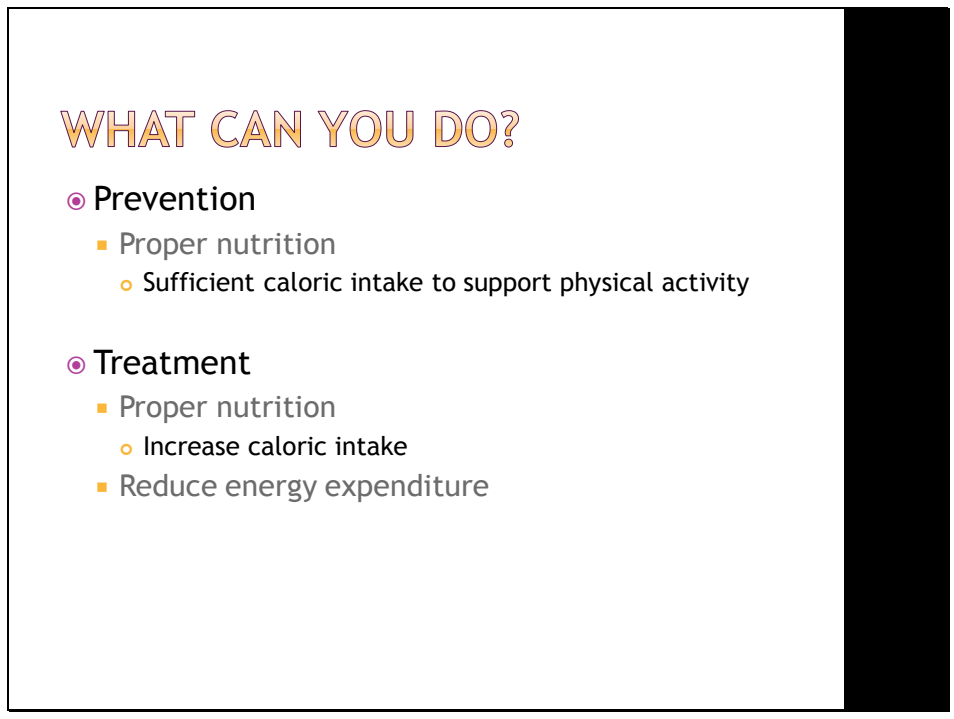

Slide 10

\section{NUTRIION IS ESSENTIAL}

๑ Eat enough calories for energy balance

- Eat adequate amounts of Carbohydrates, Protein, \& Fat

$\odot$ Avoid skipping meals

- Start everyday with a healthy breakfast

- Add snacks between meal times

๑ Eat every 3 to 4 hours 
Slide 11

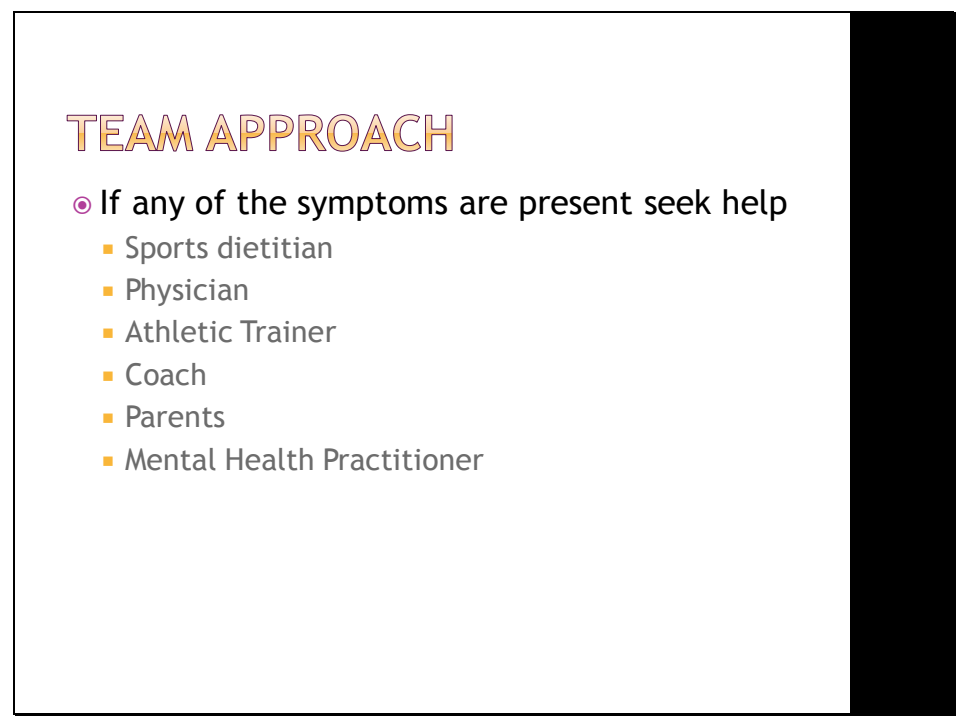

Slide 12

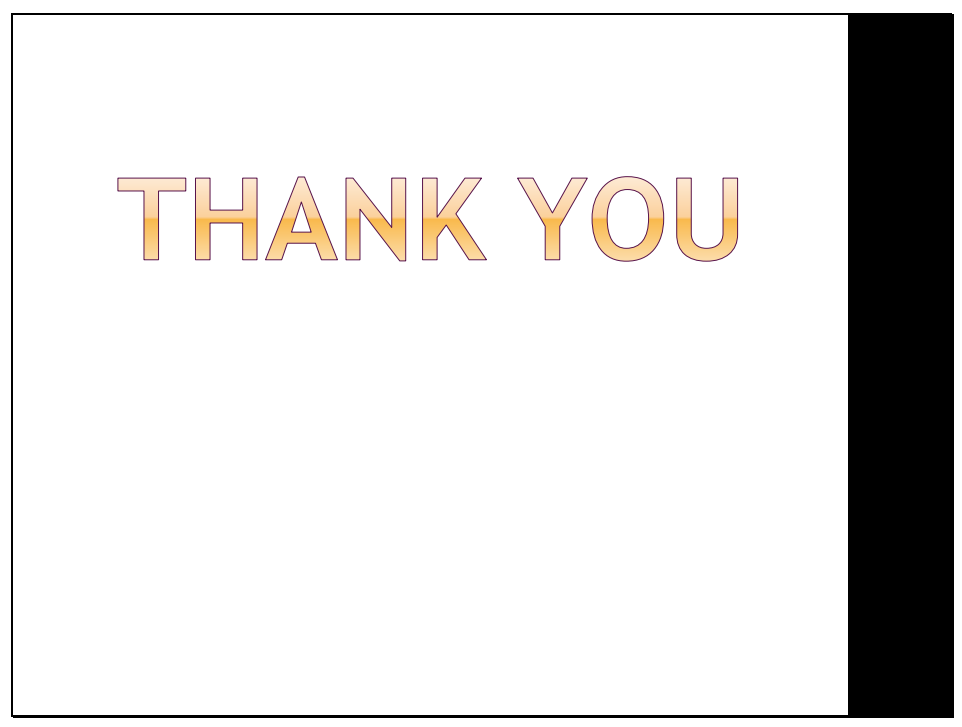


APPENDIX B

\section{EDUCATIONAL HANDOUT}




\section{Appendix B}

\section{Educational Handout}

\section{The Female Athlete Triad}
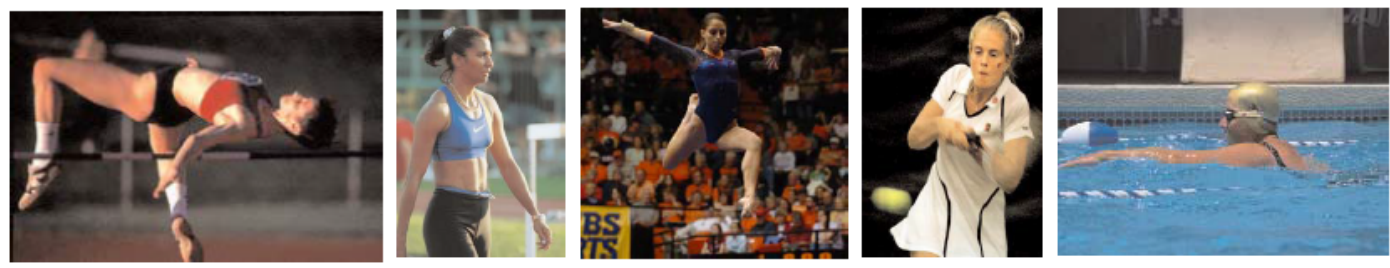

\section{What is the Female Athlete Triad?}

Sport is a great way for girls and women to build strong, healthy

bodies, self-esteem and a life-long love of physical activity.

However, some female athletes participate in sport in a way that is Less than optimal for their

health and well-being. The Female Athlete Triad is a serious health concern that has been identified among athletes, particularly girls and women in competitive sport.

THE FEMALE

A THLETE

TRIAD COALITION

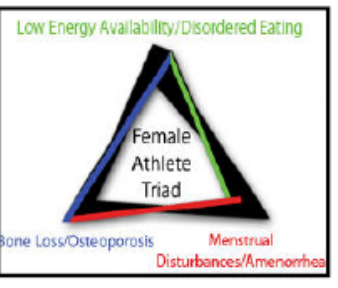

The Female Athlete Triad (Triad) refers to three health problems that are linked to each other: Low energy availability or energy deficiency ("under-fueling"), menstrual problems, and weak bones. Menstrual problems include irregular or missed periods. Bone problems can include stress fractures and reduced bone density for your age. These health problems, especially when they occur at the same time, require prompt medical attention. Having just one part of the Triad is enough, however, for any girl or woman who wants to stay active to seek help. Luckily, the key to avoiding menstrual problems and building strong bones is simple - eat enough calories to fuel your body during exercise and at rest.

\section{Under-fueling (low energy availability)}

Energy availability is defined as the amount of energy from food (calories eaten) that is available for your body after exercise (calories expended). Active girls and women who routinely expend more calories than they take in will end up in an energy (caloric) deficit. If this energy deficit is too large, your body will have too few calories or too little energy left over to maintain other normal functions, like having a menstrual period every month or developing healthy bones.

Sometimes, female athletes slip into this under-fueled state. They simply don't realize how much energy they expend during workouts and they don't eat enough to maintain a healthy weight. In other cases, athletes and physically active girls and women try to lose too much weight or lose it too quickly in order to look or perform better. They under-eat by skipping meals, avoiding all foods that contain fat or they eliminate lots of foods without making healthy substitutions. Some athletes use too much exercise relative to their caloric intake in order to lose weight quickly which can create an excessive energy deficit.

In the short-term, low energy availability or energy deficiency makes it hard to perform at your best. When you are dehydrated and low on fuel, this means you have less power, muscle strength and stamina. You will not get the benefit of improved performance from your workouts, and in fact, your performance may even get worse. You'll tire more quickly, get sick more easily and you'll recover less quickly. Girls and women who try one diet after another or who lose too much weight (or lose it too quickly) can also be slowed down by other serious problems, like iron-deficiency anemia, menstrual problems and stress fractures.

\section{Irregular or missed periods}

Low energy availability or energy deficiency disrupts the reproductive system in otherwise healthy active girls and women. The result is irregular or less frequent menstrual cycles (oligomenorrhea). Even more worrisome is when three (or more) menstrual cycles in a row are missed (amenorrhea). Eating too few calories can also delay the onset of menstruation, so that a young woman does not begin having periods by age 15 . When periods are less frequent or missed, the body makes less estrogen. Estrogen is a hormone that is absolutely necessary for building strong bones. Any menstrual irregularities must be diagnosed by a physician in order for proper care to be provided.

\section{Stress fractures and other bone problems}

Because of changes in hormones that are associated with decreased energy availability or energy deficiency, your body is not able to replace old bone cells with new healthy cells. During this time, you are at risk for poor bone health. The situation is even more alarming for physically active girls with irregular periods during their peak bone-building years (puberty to age 20). Despite the positive bone-building effects of exercise, these girls actually fail to build all the bone that is expected. It remains unclear whether this "lower-than-expected" or overall decrease in bone mass is permanent or if full "catch-up" is possible once menstruation begins.

Losing bone mass or bone density faster than you should sets the stage for stress fractures and the early onset of osteoporosis (weak bones that break easily). Bone loss is made worse by energy deficiency and under-fueling and getting too little of important nutrients like calcium and vitamin $\mathrm{D}$. 


\section{What are the risk factors for developing the Triad?}

Any thoughts, beliefs or behaviors that lead to low energy availability or energy deficiency might be considered a risk factor for developing the Triad. For example: dieting at an early age; chaotic eating habits (such as skipping meals), being unhappy with your body type, perfectionism; or believing that losing weight (or body fat) at any cost will improve performance. Taking part in sports that favor a lean body size or shape (like gymnastics, figure skating or long distance running) or sports that have weight classes (like rowing) or revealing uniforms (like swimsuits or volleyball uniforms) can also lead some girls and women to unhealthy eating habits.

\section{What are the signs of the Triad?}

You do not need to exhibit all three components of the Triad at the same time to be at risk for health problems! In the early stages, workouts and performances may not be adversely affected and standard blood test results are typically normal.

Frequent or deliberate attempts to lose weight or decrease body fat quickly or to look "more toned" or "like an athlete should" often result in chaotic eating patterns and under-fueling. Possible indicators of the Triad that need to be evaluated by a sports-minded health professional include: irregular or absent periods (or difficulty becoming pregnant); stress "reactions" or fractures; a preoccupation with weight or body size and shape that interferes with normal eating habits; noticeable weight loss; and excessive or compulsive exercise habits.

\section{What are the consequences of the Triad?}

The Triad can affect every aspect of life. Eating too few calories and nutrients can quickly lead to dehydration and electrolyte imbalances and leave you feeling more tired, anxious and irritable than usual. You may find it harder to concentrate and feel less motivated to do things you normally like to do. Athletes report that they feel as if they are training harder but their performances don't improve, or may even get worse.

Over time, the Triad increases your risk of suffering a stress fracture or an "overuse" injury and then makes it harder to train successfully for your sport.

\section{Is it normal for female athletes to stop menstruating when participating in sports?}

Although it may occur in some sports, it is never normal, desirable or acceptable. When periods stop the body is communicating that something is wrong! Any menstrual irregularity should be evaluated by a physician in order for proper treatment to begin.

\section{Why should young females and their families worry about the Triad?}

Healthy eating and exercise habits develop early and last a lifetime Because it's hard for adults to give up what they learned as children, it is important to develop smart eating habits at an early age. It is also important to choose optimal exercise and fitness activities and patterns. The teen years are the prime time to build dense bones. A lack of good bone health as a teen means a greater likelihood of bone problems later in life. Lastly, irregular or missed periods can make it more difficult to become pregnant or maintain a healthy pregnancy and have children.

Reproduced with permission from The Female Athlete Triad Coalition.

www. femaleathletetriad.org

\section{How is the female athlete Triad treated?}

The best care for a woman or girl with the Triad consists of putting together a team of experts who provide medical care and nutritional counseling, as well as a psychologist or mental health counselor to help if there are body image issues or other life concerns. The cornerstone of treating an athlete with the Triad is learning how to maintain a healthy weight by eating enough calories to cover the amount of energy expended through exercise.

Having regular periods is important. If your periods are irregular or you have not had a period for over three months (or have not started your period by age 15), see your doctor immediately. Normal monthly periods should be the goal for all female athletes-in all sports and at all levels of competition.

To avoid life-long problems, seek medical attention quickly when even one aspect of the Triad is present. For example, if you have a stress fracture or "shin splints" that won't heal, or you're enjoying your sport less and less because you are anxious about food or your weight.

\section{Even more important--how can we prevent the Triad?}

Preventing the Triad begins with a healthy attitude toward food and exercise. Since athletes come in all shapes and sizes, girls and women must be allowed to and encouraged to choose sports appropriate for their natural body type.

All physically active girls and women can do the following to prevent the Triad:

1. Keep track of your periods from month to month by writing down the number of days between cycles. Discuss these records with your physician at your next visit.

2. Know generally how many calories you eat each day. Most commercial food products have caloric values available, and there are several online sources to help you estimate how many calories you need per day to maintain your current body weight.

3. Eat every three to four hours. - Three meals a day and at least two snacks. Have a daily eating plan for when to eat to best fuel and recover from exercise. For example, competitive athletes often need to carry snacks around during the day and eat before, as well as right after practices.

4. Treat snacks as mini-meals. Choose foods that are nutritious, taste good and fit your lifestyle. For example, healthy "fast foods" like a bowl of instant oatmeal with raisins, a peanut butter sandwich or crackers with peanut butter, a low-fat milk shake or fruit smoothie, or a microwaved baked potato topped with cheese, fit the bill.

5. Track how much you exercise in a day, accounting for time, type and intensity of exercise. Adjust your food intake to account for the increased expense of energy. For example if you weigh 150 pounds and you add a 2 hour vigorous volleyball practice to your daily activities, you will burn approximately 1100 calories in addition to your normal requirements. There are many online sources to calculate how many calories are needed by an athlete who performs a wide variety of sports

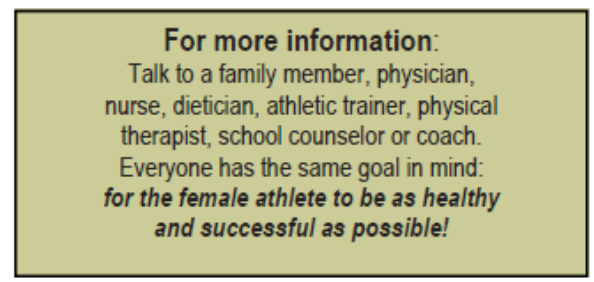


APPENDIX C

TRIAD KNOWLEDGE QUESTIONNAIRE 


\section{Appendix C}

\section{Triad Knowledge Questionnaire}

Tell us a little about you...

1. What is your birth date?

2. What is your rank in school? (Circle one)

Freshman Sophomore Junior Senior Graduate student

3. In which NCAA sport do you participate? (Circle all that apply)

$\begin{array}{llll}\text { Basketball } & \text { Cross Country } & \text { Field Hockey } & \text { Golf } \\ \text { Gymnastics } & \text { Soccer } & \text { Softball } & \text { Track and Field }\end{array}$

Volleyball

4. Are you a Nutrition major?

O Yes

O No

5. Are you an Exercise Science/Exercise Physiology major?

$\begin{array}{ll}\mathrm{O} & \text { Yes } \\ \mathrm{O} & \mathrm{No}\end{array}$

6. Have you taken a nutrition course in college?

O Yes If yes, how many?

O No

7. Have you taken any college courses in which nutrition was a component, chapter or unit?

$\mathrm{O}$ Yes If yes, how many?

No

8. Did you have nutrition included in any high school course?

O Yes If yes, how many?

O No

9. Have you ever been diagnosed with the female athlete triad?

$\begin{array}{ll}\mathrm{O} & \text { Yes } \\ \mathrm{O} & \mathrm{No}\end{array}$

10. Have you ever been diagnosed with an eating disorder?

$\begin{array}{ll}\mathrm{O} & \text { Yes } \\ \mathrm{O} & \mathrm{No}\end{array}$ 


\section{Triad Knowledge Questionnaire}

Please complete the survey to the best of your ability and thank you for participating in our study.

Have you ever heard of the Female Athlete Triad?

O Yes

O No

Which of the following conditions represent the interrelated conditions of the Female Athlete Triad?

(Check all that apply)

Low energy availability

- Heart arrhythmia

- Menstrual dysfunction

- Polycystic ovary syndrome

口 Premenstrual syndrome

Bone loss

Of the following, which are possible signs/symptoms of the Female Athlete Triad? (Check all that apply)

口 Irregular or absent menstrual cycles

Always feeling tired and fatigued

Weight gain or trouble losing weight

- Sleep disturbances

Stress fractures and frequent or recurrent injuries

A Acne on face and shoulders

Often restricting food intake

D Drive for thinness

Cold hands and feet

口 Frequent heartburn

Eating less than needed in an effort to improve performance or physical appearance 
For the following, indicate if the statement is true or false.

\begin{tabular}{|c|c|c|c|}
\hline & True & False & Don't Know \\
\hline $\begin{array}{l}\text { All females who are physically active are at greatest risk for } \\
\text { development of the Female Athlete Triad. }\end{array}$ & $\mathrm{O}$ & $\mathrm{O}$ & $\mathrm{O}$ \\
\hline $\begin{array}{l}\text { Energy deficiency is believed to be the primary cause of the } \\
\text { Female Athlete Triad. }\end{array}$ & O & $\mathrm{O}$ & $\mathrm{O}$ \\
\hline The Female Athlete Triad can be fatal. & $\mathrm{O}$ & $\mathrm{O}$ & $\mathrm{O}$ \\
\hline $\begin{array}{l}\text { Participating in athletics is the primary cause of Female Athlete } \\
\text { Triad. }\end{array}$ & O & $\mathrm{O}$ & $\mathrm{O}$ \\
\hline $\begin{array}{l}\text { The Female Athlete Triad only affects athletes' health while they } \\
\text { are participating in sports. }\end{array}$ & $\mathrm{O}$ & $\mathrm{O}$ & $\mathrm{O}$ \\
\hline $\begin{array}{l}\text { Female athletes who drink alcoholic beverages are at increased } \\
\text { risk of developing Female Athlete Triad. }\end{array}$ & $\mathrm{O}$ & $\mathrm{O}$ & $\mathrm{O}$ \\
\hline $\begin{array}{l}\text { Participation in sport(s) that require weight checks is considered a } \\
\text { risk factor for developing Female Athlete Triad. }\end{array}$ & $\mathrm{O}$ & O & $\mathrm{O}$ \\
\hline $\begin{array}{l}\text { Participation in a sport where undue emphasis is placed on having } \\
\text { a low body weight and a lean physique (i.e. figure skating, ballet, } \\
\text { gymnastics) may be a risk factor for developing Female Athlete } \\
\text { Triad. }\end{array}$ & O & $\mathrm{O}$ & $\mathrm{O}$ \\
\hline $\begin{array}{l}\text { Female athletes who feel pressure to "win at all costs" are at risk } \\
\text { for developing Female Athlete Triad. }\end{array}$ & O & $\mathrm{O}$ & $\mathrm{O}$ \\
\hline
\end{tabular}

Which of the following should an athlete engage in first when one or more the components of the Female Athlete Triad are diagnosed?

Improve energy balance to meet needs

O Take calcium supplements to improve bone health

Stop participating in sports

When are student-athletes at your university screened for Female Athlete Triad?

O As incoming freshmen or transfer students

O Each year during pre-participation physicals

O Only when signs or symptoms are identified

O Never

I I don't know 
Rank the following in order of best to worst resource for student-athletes, regarding Female Athlete Triad information and support. $(1=$ best; $8=$ worst $)$

$\begin{array}{ll} & \text { Internet } \\ \text { Parents } & \text { Athletic trainer } \\ & \text { Teammates } \\ & \text { Counselor } \\ & \text { Physician } \\ & \text { Dietitian/Nutritionist } \\ & \text { Coach }\end{array}$

Thank you again for participating in our study! 
APPENDIX D

RECRUITMENT EMAIL 


\section{Appendix D}

\section{Recruitment Email}

\section{Dear [Coach Name]:}

I am a graduate student in the Department of Nutrition here at Kent State and for my nutrition thesis I am interested in working with NCAA Division I female collegiate athletes. The purpose of my study is to determine what female collegiate athletes know about the female athlete triad and if an educational intervention can improve their knowledge. Would you consider allowing me to meet with your team to discuss my study?

If you allow your team to be recruited, the requirements would be two meetings with the team for a total estimated time of one hour over the course of the study. The first meeting would be approximately fifteen minutes but up to a maximum of a half hour if your team is receiving an educational presentation. During this meeting I will explain my study and have the athletes take a knowledge questionnaire about the female athlete triad. If your team is part of the experimental groups they may receive an educational handout and/or presentation that provide an overview of the female athlete triad. These educational materials are intended to increase the athletes' knowledge of the female athlete triad. The second and final meeting would take place two weeks after the first meeting and require about five to ten minutes for the athletes to retake the questionnaire. At the end of the study I would be happy to share my results with you and your team if interested. Participation in the study is completely voluntary and the athletes may choose not to participate or discontinue participation at any time.

I look forward to speaking with your athletic team to see if they would be interested in participating in my study. Please contact me with any questions you may have at (330) 501-1000 or jrennol1@,kent.edu. Your may also contact my advisor, Dr. Amy Miracle, at (330) 672-2649 or amiracle@kent.edu.

Thank you for your consideration,

Jessica Rennolds 
APPENDIX E

\section{CONSENT FORM}




\section{Appendix E}

\section{Consent Form}

\section{KENT STATE。}

\section{$\underline{\text { Informed Consent to Participate in a Research Study }}$}

Study Title: Impact of an educational intervention on female athlete triad knowledge in female collegiate athletes.

Principal Investigator: Amy Miracle, Ph.D.; Co-Investigator - Jessica Rennolds

You are being invited to participate in a research study. This consent form will provide you with information on the research project, what you will need to do, and the associated risks and benefits of the research. Your participation is voluntary. Please read this form carefully. It is important that you ask questions and fully understand the research in order to make an informed decision. You will receive a copy of this document to take with you.

Purpose: The purpose of this study is to determine what female collegiate athletes know about the female athlete triad and to determine if an educational intervention can improve knowledge of the triad.

\section{Procedures}

If you agree to participate in this study and sign this consent form, you will be given a pretest questionnaire in order to assess your knowledge of the female athlete triad. The first part of the questionnaire asks you to provide background information and the last part asks you questions about the female athlete triad. If you are assigned to the first experimental group there will be a presentation after the pretest and you will receive a handout to take with you. The presentation and handout are educational materials about the female athlete triad. A presentation will also be given to the second group after the pretest has been administered. If you are part of the third experimental group you will receive a handout after the pretest and if you are part of the control group you will only have to complete the pretest for this meeting. The posttest portion of this study, administered to all four groups, will take place on week three and will involve retaking the initial questionnaire.

\section{Benefits}

The potential benefits of participating in this study may include an increased knowledge of the female athlete triad. Your participation in this study will help us better understand what female collegiate athletes know about the female athlete triad. In addition, it will help us determine if education can improve knowledge of the female athlete triad. Furthermore, it may lead to the development of educational programs about the female athlete triad at universities. 


\section{Risks and Discomforts}

There are no anticipated risks associated with this research study. You may choose to skip questions or you can leave the questionnaire blank.

\section{Privacy and Confidentiality}

You will not be asked to provide your name except to sign the consent form which will be kept separate from the study questionnaire. You will be asked to provide your birth date on the questionnaire but this will NOT be used for identification purposes. Your birth date will only be used in order to match your pretest to the posttest. All consent forms and questionnaires will be kept in a secure location and only the researchers will have access to this data. Research participants will not be identified in any publication or presentation of research results.

\section{Voluntary Participation}

Taking part in this research study is entirely up to you. You may choose not to participate or you may discontinue your participation at any time. You will be informed of any new, relevant information that may affect your willingness to continue your study participation.

\section{Contact Information}

If you have any questions or concerns about this research, you may contact Amy Miracle at 330672-2649. This research study has been approved by the Kent State University Institutional Review Board. If you have any questions about your rights as a research participant or complaints about the research, you may call the IRB at 330-672-2704.

\section{Consent Statement and Signature}

I have read this consent form and have had the opportunity to have any questions answered to my satisfaction. I voluntarily agree to participate in this study. I understand that a copy of this consent will be provided to me for future reference.

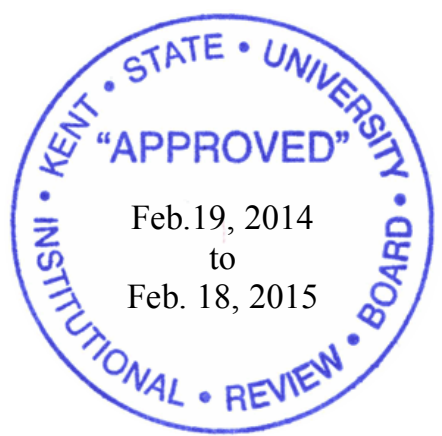


APPENDIX F

FREQUENCY DISTRIBUTIONS TABLE 
Frequency Distribution of Division I Female Collegiate Athletes Rank of Available Resources for Female Athlete Triad Information and Support $(N=44)^{\mathrm{a}}$

\begin{tabular}{|c|c|c|c|c|c|c|c|c|}
\hline $\operatorname{Rank}^{\mathrm{b}}$ & $\begin{array}{c}\text { Internet } \\
n(\%)\end{array}$ & $\begin{array}{c}\text { Parents } \\
n(\%)\end{array}$ & $\begin{array}{l}\text { ATC } \\
n(\%)\end{array}$ & $\begin{array}{c}\text { Teammates } \\
n(\%)\end{array}$ & $\begin{array}{c}\text { Counselor } \\
n(\%)\end{array}$ & $\begin{array}{l}\mathrm{MD} \\
n(\%)\end{array}$ & $\begin{array}{c}\mathrm{RD} \\
n(\%)\end{array}$ & $\begin{array}{c}\text { Coach } \\
n(\%)\end{array}$ \\
\hline 1 & $2(4.5)$ & $2(4.5)$ & $2(4.5)$ & $0(0.0)$ & $2(4.5)$ & $18(40.9)$ & $18(40.9)$ & $1(2.3)$ \\
\hline 2 & $1(2.3)$ & $1(2.3)$ & $6(13.6)$ & $1(2.3)$ & $2(4.5)$ & $16(36.4)$ & $17(38.6)$ & $0(0.0)$ \\
\hline 3 & $5(11.4)$ & $1(2.3)$ & $25(56.8)$ & $0(0.0)$ & $2(4.5)$ & $4(9.1)$ & $6(13.6)$ & $1(2.3)$ \\
\hline 4 & $12(27.3)$ & $8(18.2)$ & $7(15.9)$ & $0(0.0)$ & $8(18.2)$ & $4(9.1)$ & $0(0.0)$ & $5(11.4)$ \\
\hline 5 & $4(9.1)$ & $7(15.9)$ & $1(2.3)$ & $4(9.1)$ & $13(29.5)$ & $1(2.3)$ & $2(4.5)$ & $12(27.3)$ \\
\hline 6 & $3(6.8)$ & $8(18.2)$ & $3(6.8)$ & $4(9.1)$ & $12(27.3)$ & $0(0.0)$ & $0(0.0)$ & $14(31.8)$ \\
\hline 7 & $2(4.5)$ & $10(22.7)$ & $0(0.0)$ & $18(40.9)$ & $4(9.1)$ & $1(2.3)$ & $1(2.3)$ & $8(18.2)$ \\
\hline 8 & $15(34.1)$ & $7(15.9)$ & $0(0.0)$ & $17(38.6)$ & $1(2.3)$ & $0(0.0)$ & $0(0.0)$ & $3(6.8)$ \\
\hline
\end{tabular}

Note. ATC $=$ Certified Athletic Trainer $; \mathrm{MD}=$ Physician; $\mathrm{RD}=$ Registered Dietitian.

${ }^{a}$ Five participants excluded due to missing or multiple use of ranking numbers.

${ }^{\mathrm{b}}$ Rank $1=$ Best, $8=$ Worst. 
REFERENCES 


\section{REFERENCES}

Abood, D. A., \& Black, D. R. (2000). Health education prevention for eating disorders among college female athletes. American Journal of Health Behavior, 24(3), 209219.

Abood, D. A., Black, D. R., \& Birnbaum, R. D. (2004). Nutrition education intervention for college female athletes. Journal of Nutrition Education and Behavior, 36(3), 135-139.

American College of Sports Medicine, American Dietetic Association, \& Dietitians of Canada. (2009). Nutrition and athletic performance. Medicine \& Science in Sports \& Exercise, 41(3), 709-731.

American Psychiatric Association. (2000). Diagnostic and Statistical Manual of Mental Disorders, Fourth Edition, Text Revision (DSM-IV-TR). Arlington, VA: American Psychiatric Association. Retrieved October 5, 2013, from http://www.psych.org

American Psychiatric Association. (2013). Diagnostic and statistical manual of mental disorders, fifth edition. Arlington, VA: American Psychiatric Association. Retrieved July 15, 2013, from dsm.psychiatryonline.org

Barr, S. I. (1987). Nutrition knowledge of female varsity athletes and university students. Journal of the American Dietetic Association, 87(12), 1660-1664.

Beals, K. A. (2000). Subclinical eating disorders in female athletes. The Journal of Physical Education, Recreation \& Dance, 71(7), 23-29.

Beals, K. A. (2003). Eating disorder and menstrual dysfunction screening, education, and treatment programs: Survey results from NCAA Division 1 schools. The Physician and Sportsmedicine, 31(7), 33-38.

Beals, K. A., \& Hill, A. K. (2006). The prevalence of disordered eating, menstrual dysfunction, and low bone mineral density among US collegiate athletes. International Journal of Sport Nutrition and Exercise Metabolism, 16, 1-23.

Beals, K. A., \& Manore, M. M. (1999). Subclinical eating disorders in physically active women. Topics in Clinical Nutrition, 14(3), 14-29.

Beals, K. A., \& Manore, M. M. (2002). Disorders of the female athlete triad among collegiate athletes. International Journal of Sport Nutrition and Exercise Metabolism, 12, 281-293. 
Beals, K. A., \& Meyer, N. L. (2007). Female athlete triad update. Clinics in Sports Medicine, 26(1), 39-89.

Beals, K. A., Brey, R. A., \& Gonyou, J. B. (1999). Understanding the female athlete triad: eating disorders, amenorrhea, and osteoporosis. Journal of School Health, 69(8), 337-340.

Becker, C. B., McDaniel, L., Bull, S., Powell, M., \& McIntyre, K. (2012). Can we reduce eating disorder risk factors in female college athletes? A randomized exploratory investigation of two peer-led interventions. Body Image, 9, 31-42.

Bergouignan, A., Momken, I., Schoeller, D. A., Normand, S., Zahariev, A., Lescure, B., . . . Blanc, S. (2010). Regulation of energy balance during long-term physical inactivity induced by bed rest with and without exercise training. The Journal of Clinical Endocrinology \& Metabolism, 95(3), 1045-1053.

Burrows, M., \& Bird, S. (2000). The physiology of the highly trained female endurance runner. Sports Medicine, 30(4), 281-300.

Burrows, M., Shepherd, H., Bird, S., Macleod, K., \& Ward, B. (2007). The components of the female athlete triad do not identify all physically active females at risk. Journal of Sports Sciences, 25(12), 1289-1297.

Carlson, J. L., Curtis, M., \& Halpern-Felsher, B. (2007). Clinician practices for the management of amenorrhea in the adolescent and young adult athlete. Journal of Adolescent Health, 40, 362-365.

Carter, J. E., \& Rudd, N. A. (2005). Disordered eating assessment for college studentathletes. Women in Sport \& Physical Activity Journal, 14(1), 62-71.

Collison, S. B., Kuczmarski, M. F., \& Vickery, C. E. (1996). Impact of nutrition education on female athletes. American Journal of Health Behavior, 20(1), 14-23.

Cupisti, A., D'Alessandro, C., Castrogiovanni, S., Barale, A., \& Morelli, E. (2002). Nutrition knowledge and dietary composition in Italian adolescent female athletes and non-athletes. International Journal of Sport Nutrition and Exercise Metabolism, 12(2), 207-219. 
De Souza, M. J., Hontscharuk, R., Olmsted, M., Kerr, G., \& Williams, N. I. (2007). Drive for thinness score is a proxy indicator of energy deficiency in exercising women. Appetite, 48, 359-367.

De Souza, M. J., Toombs, R. J., Scheid, J. L., O'Donnell, E., L, W. S., \& Williams, N. I. (2010). High prevalance of subtle and severe menstrual disturbances in exercising women: confirmation using daily hormone measures. Human Reproduction, 25(2), 491-503.

De Souza, M. J., West, S. L., Jamal, S. A., Hawker, G. A., Gundberg, C. M., \& Williams, N. I. (2008). The presence of both an energy deficiency and estrogen deficiency exacerbate alterations of bone metabolism in exercising women. Bone, 43, 140148.

Frederick, L., \& Hawkins, S. T. (1992). A comparison of nutrition knowledge and attitudes, dietary practices, and bone densities of postmenopausal women, female college athletes, and nonathletic college women. Journal of the American Dietetic Association, 92(3), 299-305.

Gibbs, J. C., Williams, N. I., \& De Souza, M. J. (2013). Prevalence of individual and combined components of the female athlete triad. Medicine \& Science in Sports \& Exercise, 45(5), 985-996.

Greenleaf, C., Petrie, T. A., Carter, J., \& Reel, J. J. (2009). Female collegiate athletes: Prevalence of eating disorders and disordered eating behaviors. Journal of American College Health, 57(5), 489-496.

Harrison, J., Hopkins, W. G., MacFarlane, D. J., \& Worsley, A. (1991). Nutrition knowledge and dietary habits of elite and non-elite athletes. Australian Journal of Nutrition and Dietetics, 48, 124-127.

Heaney, S., O'Connor, H., Michael, S., Gifford, J., \& Naughton, G. (2011). Nutrition knowledge in athletes: A systematic review. International Journal of Sport Nutrition and Exercise Metabolism, 21, 248-261.

Hinton, P. S., Sanford, T. C., Davidson, M. M., Yakushko, O. F., \& Beck, N. C. (2004). Nutrient intakes and dietary behaviors of male and female collegiate athletes. International Journal of Sport Nutrition and Exercise Metabolism, 14, 389-405. 
Hoch, A. Z., Pajewski, N. M., Moraski, L., Carrera, G. F., Wilson, C. R., Hoffman, R. G., ... Gutterman, D. D. (2009). Prevalence of the female athlete triad in high school athletes and sedentary students. Clinical Journal of Sport Medicine, 19(5), 421428.

Hoek, H. W. (2006). Incidence, prevalence and mortality of anorexia nervosa and other eating disorders. Current Opinion in Psychiatry, 19(4), 389-394.

Hoek, H. W., \& van Hoeken, D. (2003). Review of the prevalence and incidence of eating disorders. International Journal of Eating Disorders, 34(4), 383-396.

Hoogenboom, B. J., Morris, J., Morris, C., \& Schaefer, K. (2009). Nutritional knowledge and eating behaviors of female collegiate swimmers. North American Journal of Sports Physical Therapy, 4(3), 139-148.

Hornstrom, G. R., Friesen, C. A., Ellery, J. E., \& Pike, K. (2011). Nutrition knowledge, practices, attitudes, and information sources of Mid-American Conference college softball players. Food and Nutrition Sciences, 2, 109-117.

Hubert, P., King, N. A., \& Blundell, J. E. (1998). Uncoupling the effects of energy expenditure and energy intake: Appetite response to short-term energy deficit induced by meal omission and physical activity. Appetite, 31, 9-19.

Ihle, R., \& Loucks, A. B. (2004). Dose-Response Relationships between energy availability and bone turnover in young exercising women. Journal of Bone and Mineral Research, 19(8), 1231-1240.

Javed, A., Tebben, P. J., Fischer, P. R., \& Lteif, A. N. (2013). Female athlete triad and its components: Toward improved screening and management. Mayo Clinic Proceedings. Mayo Clinic, 88(9), 996-1009.

Johnson, C., Powers, P. S., \& Dick, R. (1999). Athletes and eating Disorders: The National Collegiate Athletic Association study. International Journal of Eating Disorders, 26(2), 179-188.

Karpinski, C. (2012). Exploring the feasibility of an academic course that provides nutrition education to collegiate student-athletes. Journal of Nutrition Education and Behavior, 44(3), 267-270.

Kopp-Woodroffe, S. A., Manore, M. M., Dueck, C. A., Skinner, J. S., \& Matt, K. S. (1999). Energy and nutrient status of amenorrheic athletes participating in a diet 
and exercise training intervention program. International Journal of Sport Nutrition, 9, 70-88.

Kunkel, M. E., Bell, L. B., \& Luccia, B. H. (2001). Peer nutrition education program to improve nutrition knowledge of female collegiate athletes. Journal of Nutrition Education, 33(2), 114-115.

Licata, A. (2009). Bone density vs bone quality: What's a clinician to do? Cleveland Clinic Journal of Medicine, 76(6), 331-336.

Loucks, A. B. (2006). Methodological problems in studying the female athlete triad. Medicine \& Science in Sports \& Exercise, 38(5), 1020.

Loucks, A. B., \& Thuma, J. R. (2003). Luteinizing hormone pulsatility is disrupted at a threshold of energy availability in regularly menstruating women. The Journal of Clinical Endocrinology \& Metabolism, 88(1), 297-311.

Loucks, A. B., Kiens, B., \& Wright, H. H. (2011). Energy availability in athletes. Journal of Sports Sciences, 29(S1), S7-S15.

Loucks, A. B., Mortola, J., Girton, L., \& Yen, S. S. (1989). Alterations in the hypothalamic-pituitary-ovarian and the hypothalamic-pituitary-adrenal axes in athletic women. Journal of Clinical Endocrinology and Metabolism, 68, 402-411.

Loucks, A. B., Verdun, M., \& Heath, E. M. (1998). Low energy availability, not stress of exercise, alters LH pulsatility in exercising women. Journal of Applied Physiology, 84, 37-46.

Machado, P. P., Goncalves, S., \& Hoek, H. W. (2013). DSM-5 reduces the proportion of EDNOS cases: Evidence from community samples. International Journal of Eating Disorders, 46(1), 60-65.

Manore, M. M., Kam, L. C., \& Loucks, A. B. (2007). The female athlete triad: Components, nutrition issues, and health consequences. Journal of Sports Sciences, 25(S1), S61-S71.

Mencias, T., Noon, M., \& Hoch, A. Z. (2012). Female athlete triad screening in National Collegiate Athletic Association Division I athletes: Is the preparticipation evaluation form effective? Clinical Journal of Sport Medicine, 22(2), 122-125. 
Miller, S. M., Kukuljan, S., Turner, A. I., van der Plight, P., \& Ducher, G. (2012). Energy deficiency, menstrual disturbances, and low bone mass: What do exercising Australian women know about the female athlete triad? International Journal of Sport Nutrition and Exercise Metabolism, 22, 131-138.

Mudd, L. M., Fornetti, W., \& Pivarnik, J. M. (2007). Bone mineral density in collegiate female athletes: comparisons among sports. Journal of Athletic Training, 42(3), 403-408.

National Collegiate Athletic Association. (2012). 1981-82 - 2011-12 NCAA Sports Sponsorship and Participation Rates Report. Retrieved July 8, 2013, from http://www.ncaa.org/wps/wcm/connect/public/NCAA/Resources/Research/Sports +Sponsorship+and+Participation+Research

National Institutes of Health Consensus Development Panel. (2001). Osteoporosis prevention, diagnosis, and therapy. The Journal of the American Medical Association, 285(6), 785-795.

Nattiv, A., Loucks, A. B., Manore, M. M., Sanborn, C. F., Sundgot-Borgen, J., \& Warren, M. P. (2007). American College of Sports Medicine position stand: The female athlete triad. Medicine and Science In Sports and Exercise, 39(10), 18671882.

Nichols, D. L., Sanborn, C. F., \& Essery, E. V. (2007). Bone density and young athletic women. Sport Medicine, 37(11), 1001-1014.

Otis, C. L., Drinkwater, B., Johnson, M., Loucks, A., \& Wilmore, J. (1997). ACSM position stand: The female athlete triad. Medicine \& Science in Sports \& Exercise, 29(5), i-ix.

Pantano, K. J. (2006). Current knowledge, perceptions, and interventions used by collegiate coaches in the U.S. regarding the prevention and treatment of the female athlete triad. North American Journal of Sports Physical Therapy, 1(4), 195-207.

Raymond-Barker, P., Petroczi, A., \& Quested, E. (2007). Assessment of nutritional knowledge in female athletes susceptible to the female athlete triad syndrome. Journal of Occupational Medicine and Toxicology, 2, 10-20.

Reel, J. J., SooHoo, S., \& Doetsch, T. A. (2007). The female athlete triad: Is the triad a problem among division I female athletes? Journal of Clinical Sport Psychology, $1,358-370$. 
Rosenbloom, C. A., \& Jonnalagadda, S. S. (2002). Nutrition knowledge of collegiate athletes in a Division I National Collegiate Athletic Association institution. Journal of the American Dietetic Association, 102(3), 418-420.

Sanborn, C. F., Horea, M., Siemers, B. J., \& Dieringer, K. I. (2000). Disordered eating and the female athlete triad. Clinics in Sports Medicine, 19(2), 199-213.

Sanford-Martens, T. C., Davidson, M. M., Yakushko, O. F., Martens, M. P., Hinton, P., $\&$ Beck, N. (2005). Clinical and subclinical eating disorders: An examination of collegiate athletes. Journal of Applied Sport Psychology, 17, 79-86.

Shriver, L. H., Betts, N. M., \& Wollenberg, G. (2013). Dietary intakes and eating habits of college athletes: Are female college athletes following the current sports nutrition standards? Journal of American College Health, 61(1), 10-16.

Simpson, W. F., Hall, H. L., Coady, R. C., Dresen, M., Ramsay, J. D., \& Huberty, M. (1998). Knowledge and attitudes of university female athletes about the female athlete triad. Journal of Exercise Physiology Online, 1(1), 1-11.

Staurowsky, E. J., DeSousa, M. J., G, D., Gentner, N., Miller, K., Shakib, E., . . . Williams, N. (2009). Her life depends on it II: Sport, physical activity, and the health and well-being of American girls and women. East Meadow, NY: Women's Sports Foundation. Retrieved July 8, 2013, from www.WomensSportsFoundation.org

Sundgot-Borgen, J., \& Torstveit, M. K. (2003). The female athlete triad - the role of nutrition. Schweizerische Zeitschrift fuer Sportmedizin und Sporttraumatologie, 51(1), 47-52.

Sundgot-Borgen, J., \& Torstveit, M. K. (2006). Response. Medicine \& Science in Sports \& Exercise, 38(5), 1022.

The Writing Group for the ISCD Position Development Conference. (2004). Diagnosis of osteoporosis in men, premenopausal women, and children. Journal of Clinical Densitometry, 7(1), 17-26.

Thein-Nissenbaum, J. (2013). Long term consequences of the female athlete triad. Maturitas, 75, 107-112.

Thompson, S. H., \& Gabriel, M. (2004). Risk factors for the female athlete triad among female collegiate and noncollegiate athletes. Physical Educator, 61(4), 200-212. 
Torres-McGehee, T. M., Pritchett, K. L., Zippel, D., Minton, D. M., Cellamare, A., \& Sibilia, M. (2012). Sports nutrition knowledge among collegiate athletes, coaches, athletic trainers, and strength and conditioning specialists. Journal of Athletic Training, 47(2), 205-211.

Troy, K., Hoch, A. Z., \& Stavrakos, J. E. (2006). Awareness and comfort in treating the female athlete triad: Are we failing our athletes? Wisconsin Medical Journal, 105(7), 21-24.

Turner, L. W., \& Bass, M. A. (2001). Osteoporosis knowledge, attitudes, and behaviors of female collegiate athletes. International Journal of Sport Nutrition and Exercise Metabolism, 11, 482-489.

Valliant, M. W., Emplaincourt, H. P., Wenzel, R. K., \& Garner, B. H. (2012). Nutrition education by a registered dietitian improves dietary intake and nutrition knowledge of a NCAA female volleyball team. Nutrients, 4, 506-516.

Wade, G. N., \& Jones, J. E. (2004). Neuroendocrinology of nutritional infertility. American Journal of Physiology: Regulatory, Integrative \& Comparative Physiology, 287(6), R1277-R1296.

Wardle, J., Parmenter, K., \& Waller, J. (2000). Nutrition knowledge and food intake. Appetite, 34, 269-275.

Williams, N. I., \& De Souza, M. J. (2006). Female athlete triad errors and misunderstandings. Medicine \& Science in Sports \& Exercise, 38(5), 1021.

Yeager, K. K., Agostini, R., Nattiv, A., \& Drinkwater, B. (1993). The female athlete triad: disordered eating, amenorrhea, osteoporosis. Medicine \& Science in Sports \& Exercise, 25, 775-777.

Zawila, L. G., Steib, C.-S. M., \& Hoogenboom, B. (2003). The female collegiate crosscountry runner: Nutritional knowledge and attitudes. Journal of Athletic Training, $38(1), 67-74$. 